\title{
Difficulty-as-Improvement: The Courage to Keep Going in the Face of Life's Difficulties
}

\author{
Veronica X. Yan, Daphna Oyserman, Gülnaz Kiper, Mohammad Atari
}

Corresponding author Daphna Oyserman, oyserman@usc.edu. Funding for this project comes from the John Templeton Foundation Grant \#61086 to Oyserman and Yan; Mohammad Atari is currently at Harvard University. Contribution statement: All coauthors participated in initial conceptualization, study design, and initial manuscript development. Each co-author made unique contributions: Atari carried out the analyses for Study 2. Kiper and Oyserman researched and reviewed relevant literature. Kiper collected part of Study 1 data and was responsible for Studies 1 and 3 to 15 analyses with support from Atari. Yan carried out data collection for part of Study 1 and supported Studies 3 to 15 . Oyserman wrote the final version with comments from the coauthor team. 


\begin{abstract}
When a task or goal is hard to think about or do, people can infer that it is a waste of their time (difficulty-as-impossibility) or valuable to them (difficulty-as-importance). Separate from chosen tasks and goals, life can present unchosen difficulties. Building on identity-based motivation theory, people can see these as opportunities for self-betterment (difficulty-as-improvement). People use this language when they recall or communicate about difficulties (autobiographical memories, Study 1; "Common Crawl” corpus, Study 2). Our difficulty mindset measures are culture-general (Australia, Canada, China, India, Iran, New Zealand, Turkey, the U.S., Studies 3$15, N=3,532)$. People in WEIRD-er countries slightly agree with difficulty-as-improvement. Religious, spiritual, conservative people, believers in karma and a just world, and people from less-WEIRD countries score higher. People who endorse difficulty-as-importance see themselves as conscientious, virtuous, and leading lives of purpose. So do endorsers of difficulty-asimprovement -who also see themselves as optimists (all scores lower for difficulty-asimpossibility endorsers).
\end{abstract}

Keywords: culture; self and identity; identity-based motivation; difficulty mindsets; optimism, conscientiousness, character virtues, and meaning in life. 


\section{Difficulty-as-Improvement: The Courage to Keep Going in the Face of Life's Difficulties}

When a task or goal feels hard to think about or do, people can infer from this something about themselves. Maybe their odds of succeeding are low (so investing is a waste of time, termed difficulty-as-impossibility). Perhaps the task or goal is valuable to them (an identitycongruent thing to do, termed difficulty-as-importance). People have both difficulty-mindsets available in memory but differ in how much they endorse each (Fisher \& Oyserman, 2017). Shifts in context can make either more top of mind (Oyserman et al., 2018), and cultures may shape how much each is chronically accessible (O'Donnell et al., 2022). At the same time, people can experience difficulties that they do not see as task or goal related - their life can be tough to endure due to circumstances beyond their control. People can choose their goals, but not whether to have a sick parent or not to live during an economic downturn. At the same time, just as people can infer something about themselves when it feels hard to think about or work on the tasks and goals they chose for themselves, they can draw inferences about themselves from how they respond to these experiences of unchosen difficulties. Indeed, we predict that people may infer that experiencing life difficulties can be self-bettering, which we term having a difficultyas-improvement mindset.

In the current paper, we synthesize a culture-based and identity-based motivation theory (Oyserman, 2009) to examine the inferences people draw about their identities from their difficulty mindsets (difficulty-as-importance, difficulty-as-impossibility, difficulty-asimprovement). We focus on those aspects of their identities that we term identities of resilience four facets of identity associated with coping with adverse situations. Cross-culturally, these commonly include being ethical, optimistic, finding purpose, and persevering (Everly et al., 2012; Greeff \& Ritman, 2005; Lecic-Tosevski et al., 2011; Massicotte, 2021; Muki, 2021). We operationalize these with measures of character virtues, optimism, meaning in life, and 
conscientiousness. Cross-cultural literature suggests that seeing oneself in this light can be motivating and helpful. Before we detail our predictions and measures, we first outline what we mean by a culture-based approach to identity-based motivation.

\section{Identity-based Motivation Theory}

Identity-based motivation (IBM) is a social psychological theory of self-regulation, motivation, and goal pursuit (Oyserman, 2007). It predicts that people construct their identities based on both what they are thinking about (the content of their thoughts) and how thinking feels (the inferences they draw from their metacognitive experiences) while considering or engaging in tasks and goals (Oyserman, 2007; Oyserman et al., 2012; Oyserman et al., 2017). People draw inferences about who they are and could become from their experiences of ease and difficulty thinking (Oyserman et al., 2007). When it feels hard to think about or work on a task or goal, that difficulty signals that succeeding at it is important to them, a "me" or "us" thing to do (termed difficulty-as-importance). It can also signal that the odds of their succeeding at the task or goal are so low as to make persistence a waste of their time (termed difficulty-as-impossibility). People hold both difficulty-as-importance and difficulty-as-impossibility mindsets but differ in how much they endorse each (Fisher \& Oyserman, 2017). IBM theory predicts a recursive link between how people interpret their experiences of difficulty thinking about or working on tasks or goals and the content of their task-oriented identities (Oyserman, 2007, 2009, 2015). Studies use autobiographical recall and other ways to make a difficulty mindset (difficulty-as-importance or difficulty-as-impossibility) or a task-oriented identity salient to demonstrate this recursive relationship. For example, students are less confident that academics are central to their current or future possible identities when a difficulty-is-impossibility rather than a difficulty-asimportance mindset is salient (e.g., Aelenei et al., 2017; Smith \& Oyserman, 2015). And the reverse, salient academic future identities affect how much students endorse each difficulty 
mindset (Oyserman et al., 2015).

\section{Expanding IBM}

We suggest expanding IBM in two ways. First, from a focus on identities linked to tasks and goals (as a good student, as healthy) to identities of resilience (as optimistic, conscientious, virtuous, and leading a life of purpose). Second, from a focus on difficulties associated with thinking about or working on chosen tasks and goals to include life difficulties - difficulties that must be endured rather than chosen or discarded. In doing so, we draw on the cultural psychology literature detailed below to suggest that people have a difficulty-as-improvement mindset available in memory. We expect that people can consider succeeding in a task to be identity-congruent (difficulty-as-importance) or incongruent (difficulty-as-impossibility) and can consider engaging with difficulty to be character-building (difficulty-as-improvement), separate from whether they succeed or not.

\section{Culture-Based Approaches to Life Suffering}

Each society provides people with a set of implicit blueprints for how to make sense of their experiences; this set of blueprints together form its culture (Oyserman \& Yan, 2019). Having a blueprint helps people know what to expect --what ought to happen moment-tomoment and over time. It clarifies how culturally valued identities should be instantiated (Yan \& Oyserman, 2018), in what order, and when (Berntsen \& Rubin, 2004; Gelfand \& Jackson, 2016). Following the normative way of being and experiencing life events feels fluent and socially valued (Oyserman, 2017). One way people experience life difficulties is that their lives fail to fit this normative order and timing of life events. If culture provides a blueprint, part of it should address how to make sense of suffering in this and other ways. The blueprint can highlight deficiency, but it can also highlight culturally sanctioned ways forward. We consider three culture-based blueprints --deservingness, higher authority, and conservatism that are likely to be 
culture-general --found in diverse societies. As we note, the first blueprint provides explanations that may leave people feeling that difficulties are justified, and so does the last. Even the higher authority blueprint highlights a culturally sanctioned way forward --the possibility that suffering has meaning without assigning blame.

\section{Deservingness}

Deservingness culture-based blueprints imply that peoples' actions, qualities, or situation merit rewards or claims, and hence people experiencing suffering might be experiencing the consequence of their actions and deserve the outcomes they attain. If that is the case, then the way things are is moral (Ellemers et al., 2019; Jost et al., 2003; Sengupta et al., 2015). We include in this category just world beliefs --that the world is fair, and people get what they deserve (Furnham \& Gunter, 1984; Lipkus et al., 1996), and karma beliefs --past actions cause current circumstances (White \& Norenzayan, 2019; White et al., 2019). Karma, as detailed below, is central to Hindu belief systems. Both just world and karma are congruent with the idea that good things happen to good people and bad people suffer dire consequences (Feather, 1992; Lupfer \& Gingrich, 1999). If people get what they deserve, their life course reflects their character. Successful people have good qualities; people who suffer do not. Deservingness blueprints imply that life difficulties are self-made but do not point to a positive aspect of suffering.

\section{Higher Authority}

In contrast, some culture-based blueprints for making sense of suffering do so. Here we focus on spiritual and religious beliefs in which a higher authority provides a guide or even preordains the broad course of lives --life unfolds according to God's plan (Lupke, 2005). People can draw on these beliefs to understand (Stevenson \& Haberman, 1998) and even find meaning in suffering (Bowker \& Bowker, 1975; Frank1, 1946; Jonas \& Fischer, 2006). Believers can find 
that suffering has a potentially positive purpose of testing and purifying those who experience it unbidden (Gray \& Wegner, 2010). The alternative --that suffering is purposeless and happens even despite living a morally correct life --upsets the moral blueprint for order (Cook, 1979; Lupke, 2005). Public and private welfare re-establishes this order by limiting help to those deemed to have lived a morally correct life (Hansen, 2019; Katz, 1989; Rasinski, 1987). Indeed, it is not difficult to find examples of theodicy — spiritual or religion-based explanations for why good people suffer and how it can lead to betterment (though we are not claiming that people take up these belief systems instrumentally).

To concretize the idea of a higher authority blueprint, we consider some links between suffering and improvement from Western and Eastern religious teachings and rituals. First, beliefs; In Judaism, some scholars argue that God inflicts pain and suffering on the righteous to improve them (Schwartz, 1983). The Jewish prophet Isaiah says that loyally serving God may yield suffering and feeling crushed but that this provides moral rewards --a portion among the great (New International Version Bible, 2011, Isaiah 53:10-11). Christian beliefs also highlight the benefits of suffering --St. Paul describes Christians as glorying in their sufferings because they know suffering produces perseverance and that perseverance improves the character and hence a sense of hope (New International Version Bible, 2011, Romans 5:3-4). In Islam, pain and suffering provide a means for growth — the influential Muslim poet Rūmī describes pain and suffering as antecedents of spiritual growth and redemption (Chittick, 1983). In Buddhism, one of the four Noble Truths is that pain and suffering are inescapable and central to existence (Harvey, 2012; Singh, 2022). Acknowledging this makes people purer and stronger (Harvey, 2012). This idea is core to the Dalai Lama's (1995) statement that "The person who has had more experience of hardships can stand more firmly in the face of problems than the person who has never experienced suffering. From this angle, then, some suffering can be a good lesson for life." 
Hindu belief suggests that people can atone for moral transgressions in current or past lives by embracing the experience of suffering (Thrane, 2010; Whitman, 2007). In some Hindu traditions, suffering can yield self-liberation (Herman, 2018).

People familiar with their religious rituals or the rituals of the religion common in their society may experience the idea of difficulty as improvement as fluent and natural because these rituals often entail fasting and self-induced suffering as paths to self-improvement. On the Day of Atonement, the Jewish tradition is to abstain from eating, drinking, and other physical pleasures to remove oneself from mundane thoughts and actions to better concentrate on the ideals of Judaism and reconcile oneself with God (Goodman, 2018). During Ramadan, the Muslim tradition is to abstain from food and water from sunrise to sunset to purify the self and increase self-discipline and compassion for impoverished people (Azizi, 2010). During Lent, the Christian tradition is to abstain from some pleasure to recall how Jesus fasted in the wilderness (Britannica, 2020). The Hindu tradition entails accepting the pain of life (Whitman, 2007). These widespread religious traditions rest on the notion that living with difficulty purifies the soul and brings one closer to God.

\section{Conservatism}

The third culture-based blueprint for making sense of suffering is conservatism. People who endorse conservative beliefs (e.g., traditional values and ideas) assume that things are the way they are for a reason. This belief allows them to make sense of suffering-people who suffer deserve it because of their shortcomings. In this way, conservatism is compatible with deservingness beliefs. Conservatives believe that the world is a fair place in which people are responsible for themselves (Carney et al., 2008), the lazy fail (Feather, 1984; Furnham \& Bland, 1983), and people get what they deserve (Furnham \& Gunter, 1984). They see the current social organization and structure as the right ones (Jost \& Banaji, 1994, Jost et al., 2004). Hence, they 
are less interested in social change (Wakslak et al., 2007). People who endorse conservatism respect authority, moralize ingroup loyalty (Graham et al., 2009), and believe that fairness entails receiving in proportion to deservingness (Haidt, 2012; Rai \& Fiske, 2011; Skitka \& Tetlock, 1993; Skurka et al., 2020). In this way, conservatism is also compatible with and often part of religious and spiritual beliefs (Reynolds et al., 2020).

\section{Less WEIRD and WEIRD-er societies}

We have described three common culture-general blueprints for making sense of suffering. We now consider two ways these culture-general processes can also be culturespecific. We organize these differences in terms of a parcel of features summarized by Henrich and colleagues (2010) as WEIRD (Western, Educated, Industrialized, Rich, Democratic, see also Henrich, 2020). For ease, we contrast less with more WEIRD cultures. The first culture-specific process is how much people are likely to endorse difficulty-as-improvement. Cultures differ in how the three blueprints to explain suffering (deservingness, higher authority, and conservatism) are accepted or at least accessible. People in less-WEIRD cultures tend to be more likely to apply karma and just world beliefs (Furnham, 1993; White et al., 2019) and to be more religious (Pew Research Center, 2018) and conservative (Stankov, 2017). These three blueprints can remain accessible even after a substantial percentage of the population in a particular society no longer identifies as members of a religion. Consider the case of China --culture-based spiritual beliefs rooted in Buddhism, Daoism, Confucianism, and folk religions permeate Chinese worldviews (Arthur, 2019). Though few Chinese people identify as Buddhist, many more pray to Buddhas and most affirm Buddhist concepts of causal retribution and karma (Yao \& Badham, 2007). Because each implies that life difficulties can support personal growth, we expect that how much people endorse difficulty-as-improvement will be culture-specific. 
The second culture-specific process is the reasoning style that is chronically accessible. Chronically accessible reasoning style differs between less and more WEIRD cultures (e.g., Ji et al., 2001; Oyserman et al., 2002; 2009; Peng \& Nisbett, 1999; Talhelm, 2020). We draw on this literature to make two predictions. First, because they apply rules and "either-or" logic in reasoning, people in WEIRD-er societies are more likely to infer that if one explanation is true other ones cannot be. Second, because they are more likely to apply family relationships, context-based explanations, and "both-and" logic in reasoning, people in less-WEIRD societies are less likely to use judged truth of one explanation to infer that of another. Therefore, they may be more likely to simultaneously endorse various interpretations of difficulty (i.e., the correlations among them should be of a lower magnitude than in WEIRD-er ones).

\section{The Current Studies}

We test and report the results of six predictions (H1 to H6). H1 studies (Studies 1 and 2) each use a distinct methodology. In contrast, we use the same method across H2 to H6 studies. For clarity, we report on our Studies 1 and 2 separately and our other studies together with a single methods description, analysis plan, and results summary. We detail our predictions below and in Table 1, which provides our prediction summaries and the studies that tested them.

H1: People use each of the three interpretations of difficulty (difficulty-as-improvement, importance, -impossibility) in natural language. Study 1 shows that difficulty-as-improvement, difficulty-as-importance, and difficulty-as-impossibility are available in memory and can become accessible with simple memory triggers. Study 2 supports the ecological validity of difficulty mindsets by showing that people use words for difficulty in proximity ones for importance, impossibility, and improvement in the English corpora.

H2: Difficulty-as-improvement is a culture-general idea in two ways. People across societies tend to endorse difficulty as improvement, and this idea can be reliably measured using 
indices of measurement invariance.

H3: Difficulty-as-improvement is rooted in society-level culture. People endorse difficulty-as-improvement more in less-WEIRD societies (China, India, Iran, and Turkey) than in WEIRD-er ones (Australia, Canada, New Zealand, and the U.S.).

H4: Difficulty-as-improvement matters. People who endorse difficulty-as-improvement see themselves as conscientious, virtuous, and optimistic people living a life of meaning.

H5: H4 is robust to control how much people endorse difficulty-as-importance and difficulty-as-impossibility.

H6: Difficulty-as-improvement is culture-based. People who endorse difficulty-asimprovement believe more in karma and a just world. They are more religious, spiritual, and conservative. 


\section{Table 1}

Hypotheses and Studies Testing Them

\begin{tabular}{|c|c|c|}
\hline \multicolumn{2}{|r|}{ Hypothesis } & \multirow{2}{*}{$\begin{array}{l}\text { Study } \\
\text { Number }\end{array}$} \\
\hline Number & Content & \\
\hline H1 & When people talk about difficulty, they use terms related to importance, impossibility, and improvement & 1 and 2 \\
\hline $\mathrm{H} 2$ & Difficulty-as-improvement can be reliably measured across societies ${ }^{a}$ & 3 to 15 \\
\hline H3 & People in less-WEIRD societies endorse difficulty-as-improvement more than those in WEIRD-er societies & 3 to 15 \\
\hline $\mathrm{H} 4$ & $\begin{array}{l}\text { People who endorse difficulty-as-improvement find themselves to be conscientious, virtuous, optimistic, } \\
\text { and leading a life of meaning }\end{array}$ & 3 to 13 \\
\hline H5 & H4 is robust—-significant after accounting for difficulty-as-importance and difficulty-as-impossibility ${ }^{b}$ & 3 to 13 \\
\hline H6 & $\begin{array}{l}\text { People who believe in karma and a just world and who are religious, spiritual, and conservative endorse } \\
\text { difficulty-as-improvement more }\end{array}$ & 14,15 \\
\hline
\end{tabular}

Note. ${ }^{a}$ We also verified that difficulty-as-importance and difficulty-as-impossibility show measurement invariance by combining data from Studies 3-15 with previously published data from O'Donnell et al. (2022).

${ }^{\mathrm{b}} \mathrm{We}$ also tested robustness by controlling for the fixed mindset of intelligence (Dweck et al., 1995).

${ }^{c}$ We first determined if karma and just world items, and religiosity and spirituality items are best considered one or two factors each. 


\section{H1: Study 1}

\section{Sample and Methods}

Undergraduates (the University of Southern California, $n=165$; The University of Texas at Austin, $n=342$; total $N=507,64 \%$ female, $\left.M_{a g e}=19.54\right)$ received subject pool course credit to participate in a two-part (manipulation, autobiographical response) ten-minute cultural imagination study. In the experimental manipulation, students read one of four parallel texts (difficulty-as-improvement, difficulty-as-importance, difficulty-as-impossibility, control) about a culture. We asked them to imagine living in that culture (full texts, Supplemental Materials, example responses Table S1). Students randomly assigned to the difficulty-as-improvement condition read about a culture where people see the difficulties and hardships they go through in life as chances to self-improve, mature, and build character. Those in the difficulty-asimportance condition read about a culture where people see difficulties with tasks and goals as implying their importance. Those in the difficulty-as-impossibility read about a culture where people see task or goal difficulty as meaning they should switch to something else. Students in the control condition imagined living in a different culture and described an experience in this culture. The control text did not mention difficulty. Control recall instructions focused on when they understood their difficulty in the way of people in that culture.

\section{Preliminary Analysis: Content-Coding}

The second and third authors agreed on a content-coding plan, coded $10 \%$, discussed discrepancies to an agreement, and completed the coding. First, they coded responses for whether they described a difficult experience (no, yes) and coded 'Yes' responses as (1) task or goal or (2) life. Then they coded task or goal responses into four groups. (1) increased task or goal value, (2) increased effort, (3) shifting to an easier way to attain the goal or do the task, or 
(4) quitting the task or goal. In exploratory coding, they coded the domain in which difficulty occurred (e.g., school or work, relationships, finances, physical or mental health, or hobbies). Content domain results are in Supplemental Materials.

\section{Results and Discussion}

Supporting H1, $92 \%$ to $99 \%$ of respondents randomly assigned to an experimental condition recalled a congruent difficulty (only three difficulty-as-importance and five difficultyas-impossibility condition responses were too vague to code). In the difficulty-as-improvement condition $(n=129), 98.4 \%$ described a life difficulty. In the difficulty-as-importance condition $(n=126), 92.1 \%$ described difficulty with a task or goal, as did $98.4 \%$ of difficulty-asimpossibility condition participants $(n=125)$. In the difficulty-as-importance condition, people described task or goal-related difficulty as a reminder of its value $(83.3 \%)$ or stirring them to effort (14.3\%). In the difficulty-as-impossibility condition, people described difficulty as a reason to try an easier way to attain their initially desired goal $(22.4 \%)$ or quit working on that goal and find another one $(73.6 \%)$. In the control condition $(n=127), 26.8 \%$ of people spontaneously mentioned difficulty. We infer that interpretations of difficulty are available in memory --people can generate autobiographical memories relevant to difficulty-as-improvement, difficulty-as-importance, and difficulty-as-impossibility. Even without a prompt (control condition), people may report their experiences in terms of difficulties. In Study 2, we apply an alternative method -analyses of a large corpus of natural language.

\section{H1: Study 2}

\section{Sample and Methods}

Our sample was the "Common Crawl” corpus (http://commoncrawl.org), which contains snapshots of all publicly scrapable text from the Internet, totaling over 630 billion words in 
English. Our method, word embeddings, creates vectors to map the meaning of concepts in a high-dimensional space by using neural network models to represent the meaning difference (Mikolov et al., 2013). We generated 100-dimensional word vectors using the "FastText" algorithm (Bojanowski et al., 2017). Like Word2vec, FastText generates vectors using contextbased representations in which character strings (words or sub-words) are represented based on the contexts in which they most commonly occur (Mikolov et al., 2013). The distance between the vectors representing each word set pair in a high-dimensional space (e.g., cosine similarity between vectors representing those concepts) reflects common usage patterns. In large corpora like ours, these similarities capture co-occurrence and the intrinsic linguistic relationships among words (e.g., synonyms, relationships among tenses for a verb, Atari \& Dehghani, 2022).

\section{Analysis Plan}

We based our analyses on how close words related to difficulty were to words related to importance, impossibility, and improvement. Because contiguity is a relative measure, we created a high (variants of the word difficulty) and a low benchmark (words irrelevant to difficulty, importance, impossibility, or improvement) as comparisons. Before examining the corpus, we developed face-valid 15-word sets of difficulty (e.g., "difficulty," "hardship," “adversity"), importance (e.g., "important," "valuable," "worthwhile”), impossibility (e.g., “impossible," “unlikely," "pointless"), improvement (e.g., "self-improvement," "characterbuilding," "self-discipline"), variants of the difficulty word set (high benchmark, e.g., “difficulties," "challenging," "hardships") and words irrelevant to difficulty or any of our constructs (low benchmark, e.g., "banana," "word," "gray."). We share each set in full in Supplemental Materials, Table S2. We formed a distribution by calculating the cosine similarity of each word in each category against all the words in the difficulty word set. We used a one- 
way analysis of variance (ANOVA) to examine the difference between these distributions. We adjusted for pairwise comparisons using the Holm method.

\section{Results and Discussion}

Results support H1. As we graphically depict in Figure 1, the average cosign similarity of the proximity in which people use words representing difficulty to ones representing importance, impossibility, and improvement ranges from 0.33-0.37. Descriptively, this is closer to the high benchmark upper bound of 0.45 than the low benchmark lower bound of 0.14 , implying that when people communicate about difficulty, they also use words representing importance, impossibility, and improvement. Not surprisingly, our high benchmark is closer, and our low one is farther in proximity than our words about importance, impossibility, and improvement. That is, people use words in the high benchmark set at closer proximity to the difficulty word set (padjs $<.001)$ and those in the low benchmark set at farther proximity to the difficulty word set ( adjs <.001). Difficulty word set words are just as proximate to importance as to impossibility word sets $(p a d j=.99)$. People use these words in equal proximity to ones about difficulty. The proximity of each word set to difficulty is higher than that of improvement words to difficulty ones (compared to impossibility, $p$ adj $=.027$, to importance, $p$ adj $=.032$ ). We interpret our results as implying that people talk about difficulty using terminology reflecting impossibility, importance, and improvement (though the latter to a slightly lower extent).

\section{Figure 1}

Study 2: Proximity of Difficulty Words to Importance, Impossibility, and Improvement Words as Compared with High and Low Benchmark Words (Cosine Similarity Analyses) 


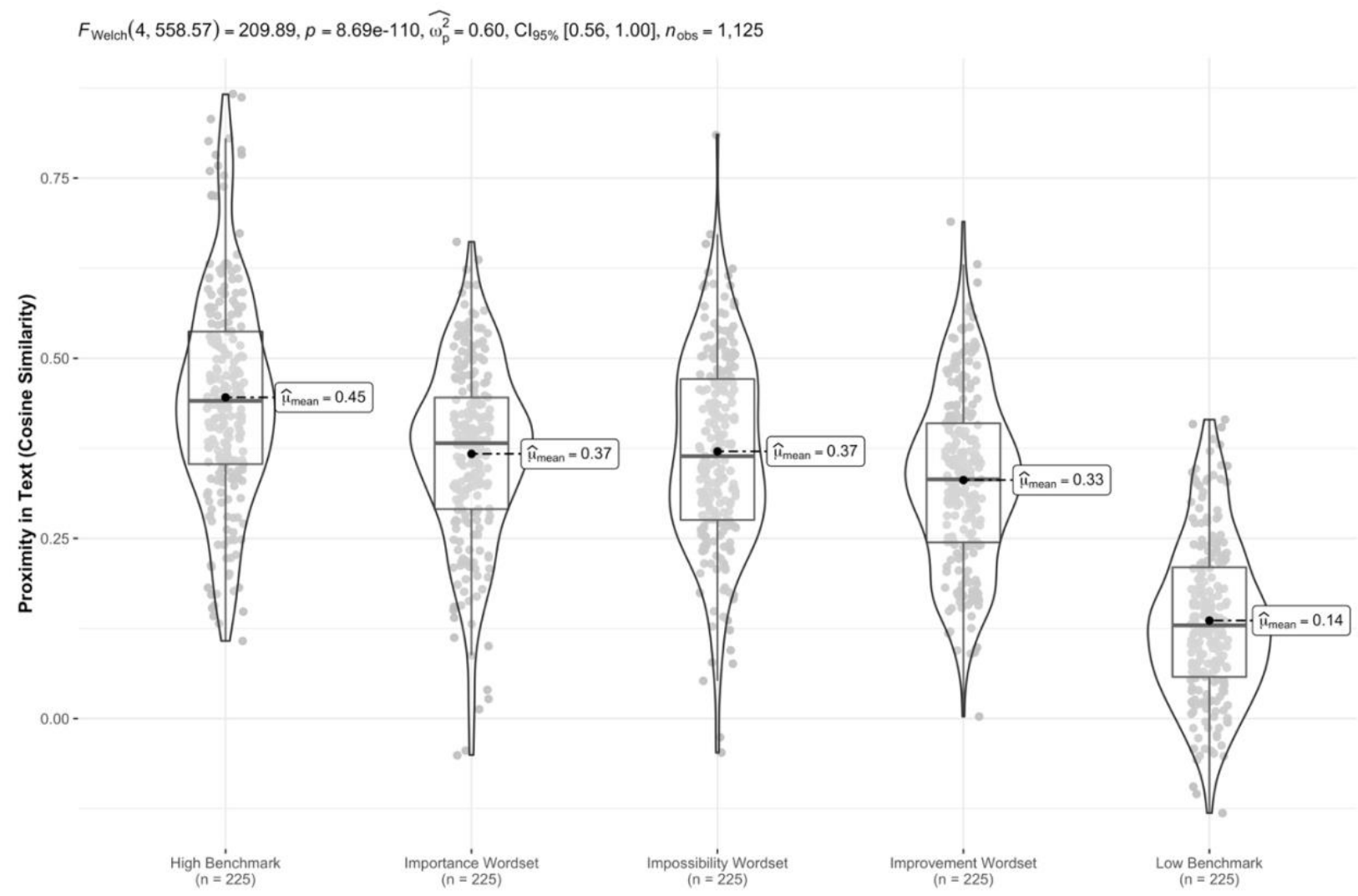

Studies 3-15

\section{Sample and Methods}

\section{Open Science}

We present our measures in Supplemental Materials and our pre-registrations, data, and analysis scripts in our Open Science Framework:

https://osf.io/yqn3k/?view only=819f1078d311485498c8b096eb653b5d.

\section{Sample}

We recruited adults from eight countries (Studies 3-15, total $N=2380$ ). We summarize our sample descriptive information in Table 2 (which also notes pre-registrations). Our predictions required different sample sizes. We detail the rationale for our sample size for each 
prediction next.

H2 tests measurement reliability and invariance --Chen and colleagues (2008) suggest a minimal sample size of 100 per group. We obtained samples of 123 to 750 per group -totaling 2380 for difficulty-as-improvement and 2870 for difficulty-as-importance and difficulty-asimpossibility. H3-H6 test associations. To detect small-to-medium correlations ( $r=.20$ to .25 ) with .80 power, we aimed to collect data from 135 participants per sample in our initial studies (Australia, Canada, and New Zealand, Studies 3-5 and 7-9). Based on our results, we aimed to collect data from 200 participants to detect all but the smallest effects in our subsequent studies (U.S, China, Iran, and Turkey, Studies 6 and 10-13). H6 also tests associations. We conducted a pilot study, which yielded an estimated effect of .15. We aimed to collect data from 350 participants in Studies 14 and 15 (conservative given that detecting this sized coefficient with .80 power and alpha of .05 requires a sample of 280).

\section{Table 2}

Description of Study Samples Testing Hypotheses 3 to 6

\begin{tabular}{lcccccc}
\hline Study & Source & Country & $N$ & Age $M(S D)$ & $\%$ Female & $\begin{array}{c}\text { Pre- } \\
\text { registered }\end{array}$ \\
\hline 3 & Prolific & Australia & 135 & $30.37(10.07)$ & 48 & No \\
4 & Prolific & Canada & 135 & $31.42(10.88)$ & 48 & No \\
5 & Prolific & New & 135 & $35.21(10.51)$ & 47 & No \\
& Zealand & United & 202 & $31.95(11.01)$ & 46 & No \\
6 & Prolific & States & & & & No \\
7 & Prolific & Australia & 135 & $30.03(9.84)$ & 49 & No \\
9 & Prolific & Canada & 135 & $32.10(11.27)$ & 48 & No
\end{tabular}




\begin{tabular}{lcccccc}
10 & Prolific & $\begin{array}{c}\text { United } \\
\text { States }\end{array}$ & 202 & $33.54(12.67)$ & 50 & No \\
11 & $\begin{array}{c}\text { Convenience } \\
\text { (social media) }\end{array}$ & China & 123 & $41.65(12.23)$ & 46 & Yes \\
12 & $\begin{array}{c}\text { Convenience } \\
\text { (social media) }\end{array}$ & Iran & 201 & $34.94(8.32)$ & 69 & Yes \\
13 & Snowball & Turkey & 188 & $43.48(11.91)$ & 45 & No \\
14 & Amazon MTurk & India & 308 & $34.31(8.70)$ & 27 & Yes \\
15 & Prolific & $\begin{array}{c}\text { United } \\
\text { States }\end{array}$ & 346 & $34.21(13.25)$ & 56 & Yes \\
$\begin{array}{l}\text { 2ndary } \\
\text { analyses }\end{array}$ & $\begin{array}{c}\text { O'Donnell et al, } \\
2022\end{array}$ & China & 365 & $29(13)$ & 63 & No \\
$\begin{array}{l}\text { 2ndary } \\
\text { analyses }\end{array}$ & $\begin{array}{c}\text { O'Donnell et al, } \\
2022\end{array}$ & India & 397 & $31.5(6)$ & 39 & No \\
$\begin{array}{l}\text { 2ndary } \\
\text { analyses }\end{array}$ & $\begin{array}{c}\text { O'Donnell et al, } \\
2022\end{array}$ & $\begin{array}{c}\text { United } \\
\text { States }\end{array}$ & 390 & $41(11)$ & 50.5 & No \\
\hline Note. Styd & & & & & \\
\hline
\end{tabular}

Note. Studies 3-10 reimbursed people 0.80 USD. To reduce the participant burden, people were randomly assigned a survey (conscientiousness and character virtues or optimism and meaning in life). Studies 11-13 provided no monetary reimbursement. Sending funds to Iran is illegal given U.S. Department of Treasury sanctions and is complicated in Turkey and China. Studies 14-15 reimbursed people 1.00 USD.

\section{Method}

Scale development. We developed the difficulty-as-improvement scale before starting data collection. First, we generated 20 face-valid statements drawing from religious beliefs and the Protestant Work Ethic scale (which translates a particular aspect of the Protestant faith into the idea that work has value in itself; Furnham \& Bland, 1983; Feather, 1984). Then we conducted two pilot studies ( $\mathrm{N}=749$ adults from Amazon Mechanical Turk) to examine the psychometric properties of these items. Next, we used exploratory factor analyses. Results supported our intuition that the 20 statements loaded onto a single factor (see Supplemental Materials Figure S1 and Table S5; loadings ranged from 0.47-0.78). We chose the four highest 
loading statements to construct our scale. We solicited feedback from colleagues who noted that the religious wording of our scale items would make it impossible for nonreligious people to respond. Hence, we reworded our scale items to be secular (see Table S5, Supplemental Materials for both versions of each statement). For example, "In a way, the struggles I have today are purifying my character to meet tomorrow's challenges" became "In a way, the struggles I have today are strengthening my character to meet tomorrow's challenges." We created translations from English to Chinese (Simplified), Farsi, and Turkish with the assistance of other native speakers and checked for clarity via back translation.

Survey protocol. We programmed our surveys in Qualtrics, except for Study 12, which took place in Iran. Qualtrics does not provide service to Iranian servers, so we used Google Forms instead. In each study, we welcomed participants, provided study information, obtained consent, presented our measures, and ended with basic demographics (age, gender).

We varied block order somewhat across studies: In Studies 3 to 10 (Australia, Canada, New Zealand, and the U.S.) and 13 (Turkey), we randomized block order (difficulty mindsets; conscientiousness; character virtue; and meaning and life and optimism) and items within each block for each participant. In Study 11 (China), we simplified our procedure to a two-block randomized order with outcome items in one block and our difficulty mindset in the second block. In Study 12 (Iran), we fixed the order of presentation as optimism, meaning in life, difficulty mindsets, conscientiousness, and virtues) because Google Forms does not allow randomization. In Studies 14 (India) and 15 (the U.S.), we randomized items in two blocks with difficulty-as-improvement, karma, belief in a just world, and religiosity in Block 1 and conservatism in Block 2. We randomized items in each block at the participant level.

\section{Measures}


Unless otherwise noted, our response scale was 6=strongly agree to 1=strongly disagree.

Difficulty-as-improvement. Table 3 provides the final secular version of our 4 -item scale and scale reliability.

Difficulty-as-importance and Difficulty-as-impossibility. We used the Fisher and Oyserman (2017) scales (Supplemental Materials Table S6 for means and standard deviations, and Table 4 for scale reliability). For ease of interpretation, here are the four items in each scale -Difficulty-as-Importance ("Sometimes if a task feels difficult to me my gut says that it really matters for me." "If a goal feels difficult to work on, I often think it might be a critical one for me." "When a task feels difficult, the experience of difficulty sometimes informs me that succeeding in the task is important for me." "Often when a goal feels difficult to attain it turns out to be worth my effort."), Difficulty-as-Impossibility ("Sometimes if a task feels difficult, my gut says it is impossible for me." "If a goal feels difficult to work on, I often think it might not be for me." "When a task feels difficult, the experience of difficulty sometimes informs me that succeeding in the task is just not possible for me." "Often when a goal feels difficult to attain it turns out to be out of my reach.”)

Identities of Resilience. We measured four facets of resilient identities. In Studies 3 to 6 and 11 to 13: (1) sense of optimism (5-item, Scheier et al., 1994) ${ }^{1}$ and (2) presence of meaning and purpose in life (5-item, Steger et al., 2006). In Studies 7 to 13: (3) conscientiousness (9-item, John \& Srivastava, 1999) and (4) character virtues (8-item forgiveness/mercy; gratitude; judgment/critical thinking; kindness; love; perseverance; prudence; self-regulation, McGrath, 2019). We report the specific items and their descriptive statistics in Supplemental Materials

\footnotetext{
${ }^{1}$ In Studies 12 and 13, we used a 6-item scale, adding an item inadvertently excluded in the other studies (see Supplemental Materials).
} 
(Tables S6 and S7) and scale reliabilities in Table 4.

Culture-based Blueprints to Understand Life Suffering. We measured five aspects of our three culture-based blueprints for making sense of suffering (deservingness, authority, and conservatism, see Table 5 for scale reliabilities). In Studies 14 and 15, we assessed belief in karma (5-item, White et al., 2019), just world belief (8-item, Lipkus et al., 1996), conservatism (2-item, Newman et al., 2018, 1=very liberal to 7=very conservative), religiosity (3-item 1=not at all religious to $7=$ very religious), and spirituality (4-item, 1=not at all spiritual to $7=v e r y$ spiritual, latter two from Koenig \& Büssing, 2010, and White et al., 2019). See Tables S8 and S9 in Supplemental Materials for scale items and descriptive statistics. 


\section{Table 3}

Difficulty-as-Improvement by Society: Cronbach's Internal Consistency, Item and Scale Means and Standard Deviations

Difficulty-as-Improvement Items

Society

\begin{tabular}{|c|c|c|c|c|c|c|c|}
\hline Australia & Canada & China & India & Iran & $\begin{array}{c}\text { New } \\
\text { Zealand }\end{array}$ & Turkey & $\begin{array}{c}\text { United } \\
\text { States }\end{array}$ \\
\hline
\end{tabular}

\begin{tabular}{|c|c|c|c|c|c|c|c|c|}
\hline \multirow[b]{2}{*}{$\begin{array}{l}\text { In a way, the difficulties I have today are } \\
\text { strengthening my character to meet tomorrow's } \\
\text { challenges. }\end{array}$} & \multicolumn{8}{|c|}{$M(S D)$ Endorsement } \\
\hline & $\begin{array}{c}4.46 \\
(1.18)\end{array}$ & $\begin{array}{c}4.66 \\
(1.04)\end{array}$ & $\begin{array}{l}4.88 \\
(0.86)\end{array}$ & $\begin{array}{l}5.10 \\
(0.92)\end{array}$ & $\begin{array}{c}4.85 \\
(1.05)\end{array}$ & $\begin{array}{c}4.57 \\
(1.16)\end{array}$ & $\begin{array}{c}5.20 \\
(1.16)\end{array}$ & $\begin{array}{c}4.52 \\
(1.07)\end{array}$ \\
\hline $\begin{array}{l}\text { Experiencing difficulty makes me grow } \\
\text { stronger. }\end{array}$ & $\begin{array}{c}4.51 \\
(1.08)\end{array}$ & $\begin{array}{c}4.72 \\
(1.05)\end{array}$ & $\begin{array}{c}5.02 \\
(0.81)\end{array}$ & $\begin{array}{c}5.07 \\
(0.89)\end{array}$ & $\begin{array}{c}4.70 \\
(1.12)\end{array}$ & $\begin{array}{c}4.59 \\
(1.13)\end{array}$ & $\begin{array}{c}4.95 \\
(1.37)\end{array}$ & $\begin{array}{c}4.54 \\
(1.03)\end{array}$ \\
\hline $\begin{array}{l}\text { Experiencing difficulty is the strongest of } \\
\text { teachers; I may temporarily feel broken, but in } \\
\text { the long run, I will be better. }\end{array}$ & $\begin{array}{c}4.24 \\
(1.15)\end{array}$ & $\begin{array}{c}4.54 \\
(1.14)\end{array}$ & $\begin{array}{c}4.86 \\
(0.96)\end{array}$ & $\begin{array}{l}5.03 \\
(0.89)\end{array}$ & $\begin{array}{l}4.75 \\
(1.10)\end{array}$ & $\begin{array}{c}4.32 \\
(1.23)\end{array}$ & $\begin{array}{c}5.06 \\
(1.25)\end{array}$ & $\begin{array}{c}4.41 \\
(1.08)\end{array}$ \\
\hline $\begin{array}{l}\text { Life is not complete without difficulty, } \\
\text { hardship, and suffering. }\end{array}$ & $\begin{array}{c}4.25 \\
(1.30)\end{array}$ & $\begin{array}{c}4.53 \\
(1.13)\end{array}$ & $\begin{array}{c}4.56 \\
(1.27)\end{array}$ & $\begin{array}{c}5.06 \\
(1.14)\end{array}$ & $\begin{array}{c}4.02 \\
(1.40)\end{array}$ & $\begin{array}{c}4.16 \\
(1.28)\end{array}$ & $\begin{array}{c}4.80 \\
(1.51)\end{array}$ & $\begin{array}{c}4.19 \\
(1.24)\end{array}$ \\
\hline
\end{tabular}

Scale Reliability, Mean, and Standard Deviation

$\begin{array}{lccccccccc}\text { Cronbach's } \alpha & .84 & .85 & .81 & .79 & .85 & .88 & .81 & .83 \\ \text { [95\% Confidence Interval] } & {[.80, .87]} & {[.82, .88]} & {[.76, .87]} & {[.75, .83]} & {[.82, .89]} & {[.86, .91]} & {[.76, .85]} & {[.81, .85]} \\ & & & & & & & \\ & & & & & & & \\ \text { Scale Mean } & 4.36 & 4.61 & 4.83 & 5.06 & 4.58 & 4.41 & 5.00 & 4.42 \\ \text { (Standard Deviation) } & (0.97) & (0.91) & (0.80) & (0.76) & (0.98) & (1.03) & (1.06) & (0.90)\end{array}$

Note. Societies in alphabetical order, $1=$ strongly disagree to $6=$ strongly agree. We present pooled data for Australia, Studies 3 and 7 $(N=270)$; Canada, Studies 4 and $8(N=270)$; New Zealand Studies 5 and $9(N=270)$; the U.S. Studies 6,10 , and $15(N=750)$. 


\section{Table 4}

Studies 3-13: Cronbach's a Reliability of Interpretations of Difficulty and Identity of Resilience Measures by Society

\begin{tabular}{|c|c|c|c|c|c|c|c|}
\hline \multirow[t]{2}{*}{ Measure } & \multicolumn{7}{|c|}{ Cronbach's $\alpha$ by Society } \\
\hline & Australia & Canada & China & Iran & New Zealand & Turkey & The U.S. \\
\hline \multicolumn{8}{|l|}{ Interpretation of Difficulty } \\
\hline Difficulty-as-Importance & $\begin{array}{c}.83 \\
{[.80, .86]}\end{array}$ & $\begin{array}{c}.81 \\
{[.78, .85]}\end{array}$ & $\begin{array}{c}.90 \\
{[.87, .93]}\end{array}$ & $\begin{array}{c}.81 \\
{[.77, .85]}\end{array}$ & $\begin{array}{c}.82 \\
{[.78, .85]}\end{array}$ & $\begin{array}{c}.79 \\
{[.74, .84]}\end{array}$ & $\begin{array}{c}.78 \\
{[.75, .80]}\end{array}$ \\
\hline Difficulty-as-Impossibility & $\begin{array}{c}.86 \\
{[.84, .89]}\end{array}$ & $\begin{array}{c}.89 \\
{[.87, .91]}\end{array}$ & $\begin{array}{c}.87 \\
{[.84, .91]}\end{array}$ & $\begin{array}{c}.81 \\
{[.77, .86]}\end{array}$ & $\begin{array}{c}.89 \\
{[.87, .91]}\end{array}$ & $\begin{array}{c}.79 \\
{[.74, .84]}\end{array}$ & $\begin{array}{c}.87 \\
{[.86, .89]}\end{array}$ \\
\hline \multicolumn{8}{|l|}{ Identity of Resilience } \\
\hline Conscientiousness & $\begin{array}{c}.87 \\
{[.85, .90]}\end{array}$ & $\begin{array}{c}.86 \\
{[.84, .89]}\end{array}$ & $\begin{array}{c}.73 \\
{[.65, .80]}\end{array}$ & $\begin{array}{c}.80 \\
{[.76, .84]}\end{array}$ & $\begin{array}{c}.86 \\
{[.84, .89]}\end{array}$ & $\begin{array}{c}.82 \\
{[.78, .86]}\end{array}$ & $\begin{array}{c}.84 \\
{[.83, .86]}\end{array}$ \\
\hline Virtuousness & $\begin{array}{c}.69 \\
{[.63, .74]}\end{array}$ & $\begin{array}{c}.71 \\
{[.65, .76]}\end{array}$ & $\begin{array}{c}.81 \\
{[.76, .86]}\end{array}$ & $\begin{array}{c}.77 \\
{[.72, .81]}\end{array}$ & $\begin{array}{c}.75 \\
{[.70, .79]}\end{array}$ & $\begin{array}{c}.80 \\
{[.75, .84]}\end{array}$ & $\begin{array}{c}.72 \\
{[.69, .75]}\end{array}$ \\
\hline Having Meaning in Life & $\begin{array}{c}.93 \\
{[.92, .95]}\end{array}$ & $\begin{array}{c}.93 \\
{[.92, .95]}\end{array}$ & $\begin{array}{c}.86 \\
{[.82, .90]}\end{array}$ & $\begin{array}{c}.90 \\
{[.88, .92]}\end{array}$ & $\begin{array}{c}.93 \\
{[.92, .95]}\end{array}$ & $\begin{array}{c}.85 \\
{[.82, .88]}\end{array}$ & $\begin{array}{c}.91 \\
{[.90, .92]}\end{array}$ \\
\hline Optimism & $\begin{array}{c}.84 \\
{[.80, .87]}\end{array}$ & $\begin{array}{c}.84 \\
{[.81, .87]}\end{array}$ & $\begin{array}{c}.65 \\
{[.55, .74]}\end{array}$ & $\begin{array}{c}.70 \\
{[.64, .77]}\end{array}$ & $\begin{array}{c}.86 \\
{[.84, .89]}\end{array}$ & $\begin{array}{c}.66 \\
{[.58, .74]}\end{array}$ & $\begin{array}{c}.83 \\
{[.81, .85]}\end{array}$ \\
\hline
\end{tabular}

Note. In Australia, Canada, New Zealand, and the U.S., we assessed meaning in life and optimism in one study and conscientiousness, and virtues in another, including interpretations of difficulty in both studies. We report alpha reliabilities for difficulty-as-importance and difficulty-as-impossibility for aggregated datasets (Australia $N=270$, Canada $N=270$, New Zealand $N=270$, the U.S. $N=404$ ). 
Table 5

Studies 14-15: Measures of Deservingness and Authority Blueprints, Reliability by Society

Measure

Cronbach's $\alpha$ [95\% Confidence Interval] or Pearson's $r$

India

United States

Deservingness

Karma

$.80[.76, .83]$

$.84[.82, .86]$

Belief in Just World

$.84[.81, .86]$

$.87[.85, .88]$

Authority

Religiosity

$.85[.82, .88]$

$.94[.93, .94]$

Spirituality

$.86[.84, .89]$

$.94[.93, .94]$

Conservatism (as Pearson's $r$ )

$.94[.93, .95]$

$.97[.97, .98]$

\section{Analysis Plan}

We used the R v. 4.1 programming language (R Core Team, 2019). For H2, we used the psych package (v. 2.1; Revelle, 2021) for Cronbach's $\alpha$ and the lavaan (v. 0.6; Rosseel, 2012) and semTools packages (v. 0.5-5; Jorgensen et al., 2021) for measurement invariance. For H3, we used stats (R Core Team, 2019) for linear regression (predictor: WEIRD-er/less-WEIRD, outcome: difficulty-as-improvement). For H4 and H5, we used lme4 (v. 1.1-23; Bates et al., 2015) in a random-intercepts mixed-effects regression for each identity outcome (fixed effects: interpretations of difficulty, random effects: society (Australia, Canada, China, Iran, New Zealand, Turkey, and the U.S.) with unstandardized predictors For H5, we used the H4 models, adding difficulty-as-impossibility and difficulty-as-importance as predictors. For H6, we pooled Study 14 and 15 data and confirmatory factor analyses to test the separateness of belief in karma from a just world and of religiosity from spirituality. We used $p s y c h$ (v. 2.1; Revelle, 2021) for correlational analyses and stats (R Core Team, 2019) for linear regressions. We show the multivariate regression with all predictors and study as a dummy-coded fixed effect (Study 14=0, 
Study 15=1) in Supplemental Materials (Table S15 and Figure S3).

\section{Results}

\section{H2: Our Constructs Can be Reliably Measured Across Societies}

Results support H2. Our difficulty-as-improvement scale is reliable (Table 3). We can meaningfully compare difficulty-as-improvement across populations given that our analysis supports configural (construct structure), metric (item factor loadings), and scalar (item intercepts) measurement invariance (Table 6, see Supplemental Materials for details). We also verified difficulty-as-importance and difficulty-as-impossibility measurement invariance (including data from O'Donnell et al., 2022, to increase the stability of our results). We found evidence for configural and metric invariance. That is, difficulty-as-importance items load onto a single factor, as do difficulty-as-impossibility ones. Items can be assumed to load onto each factor the same way in more- and less-WEIRD groups (for details, see Supplemental Materials, Tables S3, and S4). Our results suggest people across societies understand difficulty-asimportance, difficulty-as-impossibility, and difficulty-as-improvement similarly.

\section{Table 6}

Difficulty-as-Improvement Measurement Invariance (MI) Models Across Eight Societies

\begin{tabular}{lccccccc}
\hline Model & $\chi^{2}$ & $\Delta \chi^{2}$ & $d f$ & $\Delta d f$ & CFI & $\Delta$ CFI & BIC \\
\hline Configural & 46.92 & -- & 16 & -- & .990 & -- & 25549 \\
Weak MI & 78.40 & 23.58 & 37 & 21 & .990 & .001 & 25417 \\
Strong MI & 195.63 & $119.67^{* * *}$ & 58 & 21 & .952 & .038 & 25371 \\
Strict MI & 373.14 & $120.40^{* * *}$ & 65 & 7 & .890 & .061 & 25494 \\
\hline
\end{tabular}

Note. ${ }^{* * *} p<.001$. Configural=equal structure, varying loadings, intercepts, and residual variances; Weak MI = equal structure and loadings, varying intercepts and residual variances; Strong MI = equal structure, loading, and intercepts, varying residual variances; Strict MI = equal structure, loading, intercepts, and residual variances; $d f=$ degrees of freedom; $\mathrm{CFI}=$ comparative fit index; $\mathrm{BIC}=$ Bayesian information criterion, $\mathrm{BIC}$ accounts for fit and penalizes 
for model complexity -lower values indicate a better solution for the trade-off between model complexity and fit. Our four multigroup confirmatory factor analysis models entailed increasing equality constraints on factor loadings, intercepts, and residual variances. We used Cheung and Rensvold's (2002) $\Delta \mathrm{CFI} \leq 0.01$ threshold to demonstrate invariance and looked for the lowest Bayesian Information Criterion (BIC), finding the lowest BIC if intercepts are constrained across groups. This approach favors strong measurement invariance over other models.

\section{H3: People Endorse Difficulty-as-Improvement More in Less-WEIRD than WEIRD-er}

\section{Societies}

Results support H3. As Figure 2 depicts graphically, linear regression analyses reveal that in less-WEIRD societies people endorsed difficulty-as-improvement more, $F(1,2377)=129.2, p$ $<.001, R^{2}$ Adjusted $=.05$. On average, in WEIRD-er societies, people were closer to the "slightly agree" option $(b=4.44, S E=.02)$. In less-WEIRD societies, they were closer to the "agree" option $(b=4.90, S E=.03)$. Table 3 provides scale means and $S D$ s.

\section{Figure 2}

Mean Endorsement of Difficulty-as-Improvement in less-WEIRD (left plot) and WEIRD-er Societies (right plot) 
Figure 2
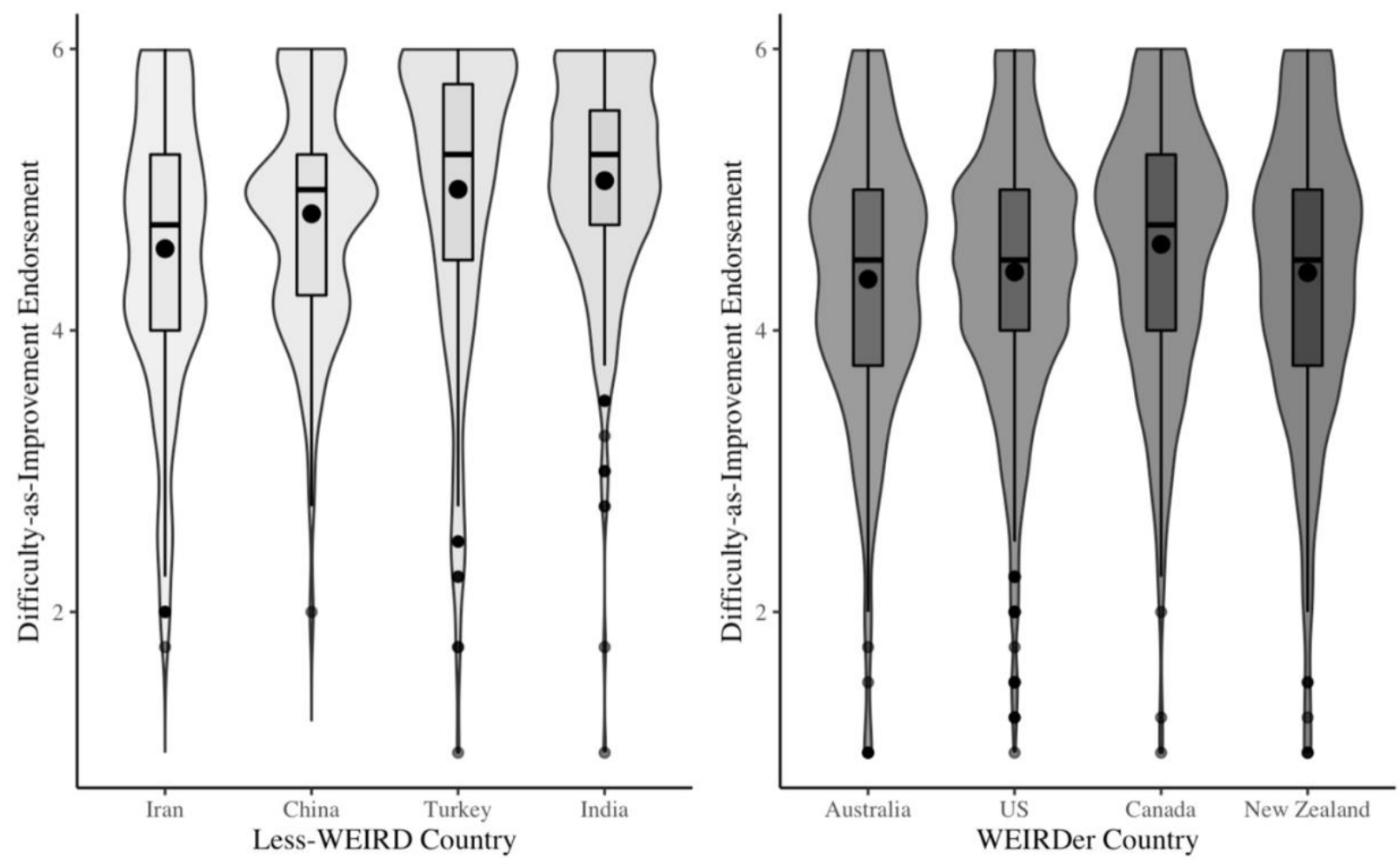

Note. Black dots represent means; horizontal lines cutting across the boxplots represent medians; each box represents the interquartile range; on each side of the boxplot is a probability density distribution of the data smoothed by a kernel density estimator. Data are combined across studies when multiple samples were collected from a given society.

We explored if culture also predicted how much people endorsed difficulty-asimportance and difficulty-as-impossibility. Our results suggest that people in WEIRD-er societies endorse difficulty-as-impossibility more (WEIRD-er $b=3.16, S E=.03$, lessWEIRD $b=2.50, S E=.05, F(1,1722)=139, p<.001$, R2Adjusted $=.07)$ and do not differ in how much they endorse difficulty-as-importance (WEIRD-er $b=4.04, S E=.03$, lessWEIRD $b=3.97, S E=.04, F(1,1721)=2.42, p=.120$, R2Adjusted $=.0008)$. The distinct pattern of differences by mindset suggests that effects are not driven by response bias.

We also examined the size of the correlations among the difficulty mindsets. As revealed in Table 7, correlations between each pair of difficulty mindsets were of greater magnitude in WEIRD-er compared to less-WEIRD societies. This pattern supports our inference that people in 
less-WEIRD societies are more likely to infer that multiple ideas can be true simultaneously (what we term "both-and" reasoning style). In contrast, people in WEIRD-er societies are more likely to infer that if one idea is true, others are not (what we term an "either-or" reasoning style). 


\section{Table 7}

Correlations Between Interpretations of Difficulty in less and more WEIRD Cultures

\begin{tabular}{ccccc}
\hline $\begin{array}{c}\text { Interpretation of Experienced } \\
\text { Difficulty Measures }\end{array}$ & Pearson's $r[95 \%$ CI] by culture type & Fisher's $z$ & $p$ \\
\hline \multicolumn{2}{c}{ Comparison Pair } & WEIRD-er & Less WEIRD & Difference between Correlations \\
\hline Improvement & Importance & $.65[.61, .68]$ & $.31[.23, .38]$ & 8.54 \\
Improvement & Impossibility & $-.35[-.39,-.30]$ & $-.13[-.21,-.04]$ & 4.37 \\
Importance & Impossibility & $-.26[-.31,-.21]$ & $-.05[-.14, .04]$ & 4.001 \\
\hline
\end{tabular}


DIFFICULTY-AS-IMPROVEMENT SUPPLEMENTAL MATERIALS 1

\section{H4: People Who Endorse Difficulty-As-Improvement See Themselves As Conscientious,}

\section{Virtuous, Optimistic, And Living A Meaningful Life.}

Results support H4. The more people endorsed difficulty-as-improvement, the more they viewed themselves as being conscientious $(b=.21, S E=.03, p<.001)$, virtuous $(b=.24, S E=$ $.02, p<.001)$, optimistic $(b=.32, S E=.03, p<.001)$, and having a life of meaning and purpose $(b=.42, S E=.03, p<.001)$.

\section{H5: H4 is Robust to Controlling for Individual Differences in Difficulty-as-Importance and}

\section{Difficulty-as-Impossibility}

Results support H5. We graphically display the unstandardized regression coefficients for each difficulty mindset in Figure 3. The association between difficulty-as-improvement and each identity-construction outcome was robust. Controlling for the effects of difficulty-as-importance and difficulty-as-impossibility, people who endorsed difficulty-as-improvement were more likely to view themselves as conscientious $(b=.08, S E=.02, p=.001)$, virtuous $(b=.14, S E=.02, p<$ $.001)$, optimistic $(b=.20, S E=.03, p<.001)$, and having a life of meaning and purpose $(b=.25$, $S E=.04, p<.001)$.

We also explored the pattern of effects for difficulty-as-importance and difficulty-asimpossibility. Controlling for the effect of difficulty-as-improvement and difficulty-asimpossibility, people who more strongly endorsed difficulty-as-importance experienced themselves as more conscientious $(b=.12, S E=.02, p<.001)$, more virtuous $(b=.14, S E=.02$, $p<.001)$, and as having more purpose and meaning in life $(b=.19, S E=.04, p<.001)$. How much they endorsed difficulty-as-importance did not predict their optimism $(b=.03, S E=.03, p$ $=.399$ ) once their difficulty-as-improvement and difficulty-as-impossibility scores were added to the equation. People who more strongly endorsed difficulty-as-impossibility were less 
conscientious $(b=-.27, S E=.02, p<.001)$, reported less character virtue $(b=-.12, S E=.02, p<$ $.001)$, were less optimistic $(b=-.36, S E=.03, p<.001)$, and found less meaning in life $(b=-.28$, $S E=.03, p<.001)$, controlling for how much they endorsed the two other interpretations of difficulty.

\section{Figure 3}

Each Interpretation of Difficulty is Uniquely Associated with Identities of Resilience

Figure 3

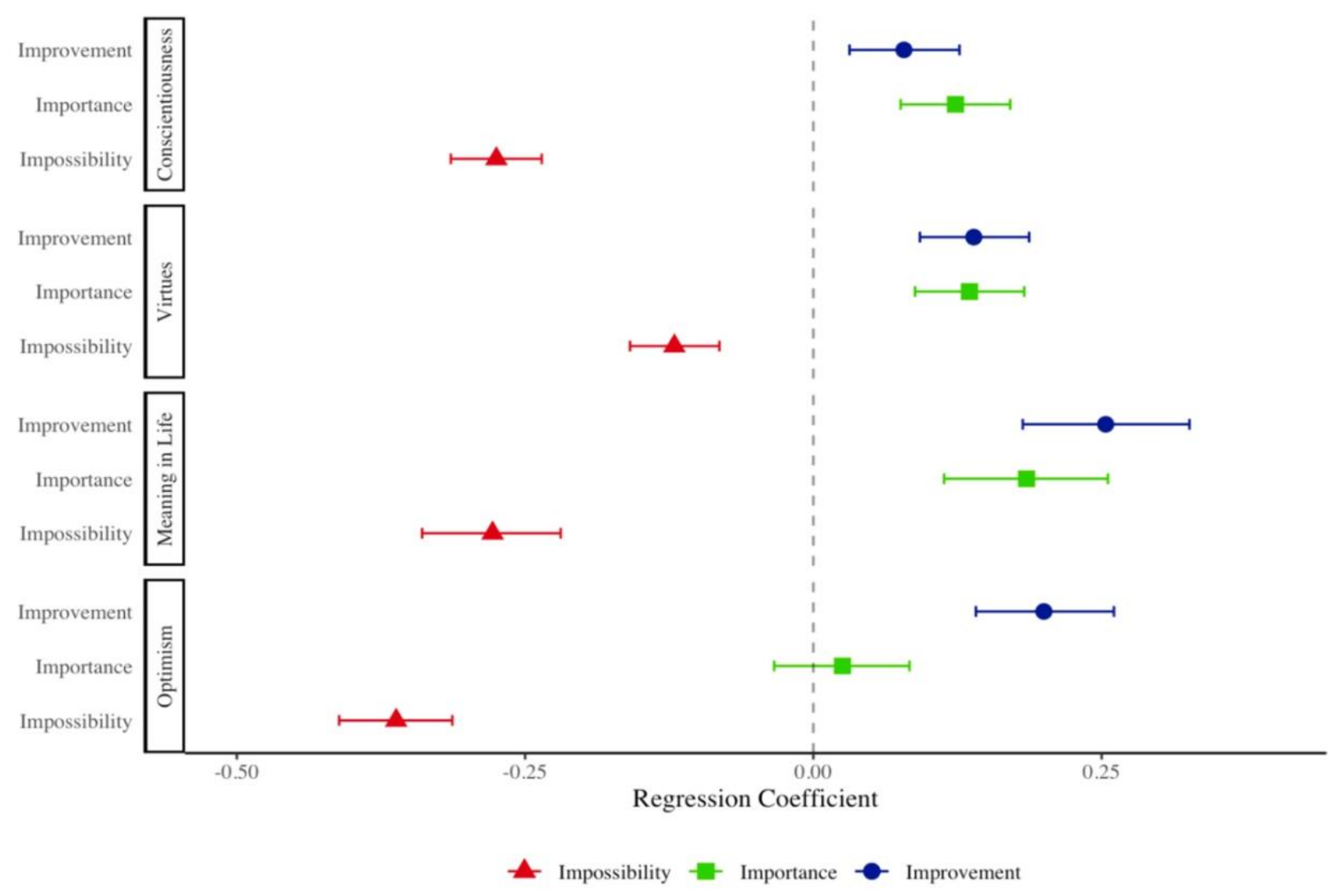

Note. Points represent unstandardized beta coefficients. Whiskers represent $95 \%$ confidence intervals. Effects are from linear mixed-effects models with difficulty-as-impossibility, difficulty-as-importance, and difficulty-as-improvement treated as fixed effects and society treated as the random effect. In each model, the outcome is one of the identity variables. The dotted line denotes 0 - effects that overlap this line are non-significant - all other effects, $p<$ 
.001. Color and shape signify predictor variables (red triangles = difficulty-as-impossibility, green squares = difficulty-as-importance, blue circles = difficulty-as-improvement).

As a final robustness check, we included a fourth control: the fixed mindset of ability (Dweck et al., 1995) in Studies 3-13 (see Supplemental Materials, Supplemental Analyses, and Table S11 for details about these items). Fixed ability mindset was correlated more with difficulty-as-impossibility ( $r$ s ranged .55 to .70 ) than with difficulty-as-importance ( $r$ s ranged .23 to .15) or with difficulty-as-improvement ( $r$ s ranged -.30 to -.01; see Supplemental Materials, Table S12). The pattern of results that difficulty-as-improvement, difficulty-as-importance, and difficulty-as-impossibility each uniquely add to the variance explained in identity construction is unaffected by the inclusion of this control (see Supplemental Materials Table S13 and Figure S2).

H6: People Who More Strongly Endorse Karma and Just World Beliefs and Who are More

\section{Religious, Spiritual, and Conservative Also Endorse Difficulty-as-Improvement More}

Results support H6. Believing in karma ( $r=.59)$ and a just world $(r=.56)$, being religious $(r=.49)$, spiritual $(r=.48)$, and conservative $(r=.20$, all $p s<.001)$ were each associated with endorsing difficulty-as-improvement. Results support our pre-registered prediction that these culture-based blueprints would matter. Their correlations are presented as a matrix in Supplemental Materials Table S14.

Next, we conducted five univariate regression analyses. In each, we entered difficultyas-improvement as the dependent variable, and karma, just world beliefs, religiosity, spirituality, or conservatism as the unstandardized predictor variable. As depicted graphically in Figure 4, more conservative $(b=.14, S E=.03, p<.001)$, spiritual $(b=.30, S E=.03, p<.001)$, and religious $(b=.28, S E=.02, p<.001)$ people who believed in karma $(b=.50, S E=.03, p<.001)$ 
and a just world $(b=.62, S E=.04, p<.001)$ scored higher in difficulty-as-improvement. As detailed in Table S15 (Supplemental Materials), follow-up analyses, adding dummy-coded society as a control, reduced the size of these associations (karma, $b=.23$, just world $b=.30 p$ s $<$ .001 , spirituality $b=.09, p=.033$, religiosity $b=.03, p=.446$, conservatism $b=-.05 p=.017$ ), suggesting that some effects may be specific to the society within which a particular blueprint is embedded.

\section{Figure 4}

Predicting Difficulty-as-improvement from Conservatism, Higher Authority, and Deservingness

Figure 4

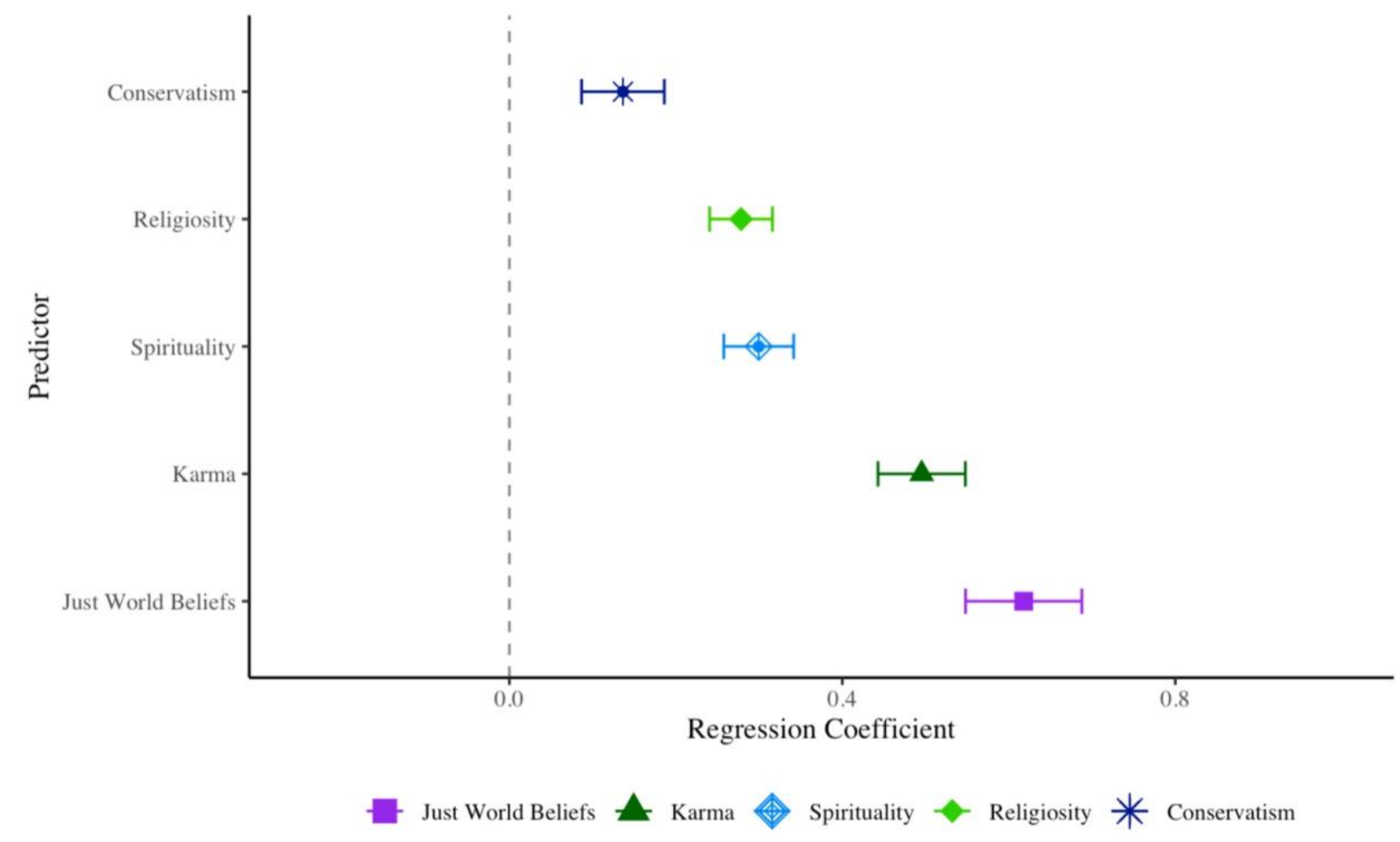

Note. Our forest plot displays the unstandardized regression coefficient of each predictor on difficulty-as-improvement in univariate regression analyses. Whiskers represent $95 \%$ confidence intervals. The unstandardized regression coefficient is represented with a geometric 
DIFFICULTY-AS-IMPROVEMENT SUPPLEMENTAL MATERIALS 5

shape. Whisker plots are all to the right of 0 , revealing significant associations, $p \mathrm{~s}<.001$.

\section{General Discussion}

We applied a culture-based understanding of identity-based motivation theory to make six predictions. First (H1, Studies 1 and 2), people can recall times in their lives when task difficulty signaled its inherent value (difficulty-as-importance) or indicated the need to shift (to another goal or an easier route, difficulty-as-impossibility) or times when they experienced a life difficulty. Our corpus analyses reveal that people use words relevant to difficulty-as-importance, difficulty-as-impossibility, and difficulty-as-improvement when they talk about difficulty. Second, difficulty-as-improvement is a culture-general construct $(\mathrm{H} 2$, Studies 3 to 15 and secondary data analyses). It is endorsed and is measurable in more and less WEIRD societies (strong measurement invariance: configural, metric, and scalar). Third, difficulty-asimprovement reveals culture-specificity. People endorse it more in less WEIRD than WEIRD-er societies (H3, Studies 3 to 15). Fourth, it matters (H4, (Studies 3 to 13). People who endorse difficulty-as-improvement are more likely to perceive themselves as conscientious, virtuous, and optimistic people who lead lives of purpose and meaning. Fifth (H5, Studies 3 to 13), these patterns are robust to how much people endorse difficulty-as-importance, difficulty-asimpossibility, and as a final control, fixed ability mindset. Sixth (H6, Studies 14 and 15), difficulty-as-improvement is rooted in culture-based beliefs --religiosity, spirituality, conservatism, belief in karma, and a just world. Even though difficulty-as-importance and difficulty-as-improvement are associated, each uniquely adds to the variance explained in each identity of resilience. Moreover, difficulty-as-improvement, not difficulty-as-importance, is associated with optimism for the future.

\section{Implications}


DIFFICULTY-AS-IMPROVEMENT SUPPLEMENTAL MATERIALS 6

\section{Identity-based Motivation Theory}

Previous IBM theorizing and empirical work focused on the interplay between task or goal-focused identities such as 'good student' or 'healthy' and difficulty-as-importance and difficulty-as-impossibility interpretations of difficulty with tasks and goals (e.g., Aelenei et al., 2017; Oyserman et al., 2007; 2018, 2021; Smith \& Oyserman, 2015). For example, students guided to interpret difficulty-as-importance are more likely to subsequently report that academics are central to their identity (Smith \& Oyserman, 2015). They are more likely to believe that they would work on their school-focused possible identities (Aelenei et al., 2017). They generate more school-focused possible identities when asked to describe their future self (Oyserman et al., 2018).

Our results expand IBM in multiple ways. First, they expand the reach of IBM theory from difficulty with tasks and goals to difficulty arising from life circumstances. We showed that our newly developed measure of difficulty-as-improvement is empirically distinct from difficulty-as-importance and difficulty-as-impossibility and a fixed/growth ability mindset (Dweck et al., 1995). Second, our results expand IBM theory from its focus on goal-related identities to a more general focus on identities of resilience. We show that people interpret both their task and goal-related difficulties and their life difficulties as having consequences for who they are. Each difficulty mindset uniquely predicts the extent to which people see themselves as conscientious, virtuous, optimistic, and leading a life of purpose and meaning.

\section{Conscientiousness, Character Virtues, Optimism, and Meaning in Life}

Our finding that interpretations of difficulties with tasks and goals and life are associated with experiencing oneself as a conscientious, virtuous, optimistic person whose life has meaning contributes to the psychological literature on predictors of these attributes. Prior studies 
document associations with other psychological, socio-familial, and socio-structural predictors. These psychological predictors include an internal locus of control (Taş \& İskender, 2018), scoring high in autonomy, competence, relatedness, and beneficence (Martela et al., 2018), and spirituality (Ivtzan et al., 2013). Previously explored socio-familial and socio-structural predictors include parental warmth (Hjelle et al., 1996), trusting others during adolescence (Eisner, 2014), and socioeconomic status (Ek et al., 2004).

\section{Cultural Generalizability and Specificity}

Behavioral scientists tend to study close-at-hand and easy-to-access people from WEIRD-er societies (Oyserman, 2017) and hence cannot tell which psychological processes are culturally generalizable and which are culture-specific (e.g., Apicella et al., 2020; Henrich et al., 2010; Rad et al., 2018). Culturally generalizable processes should be rooted in experiences people across cultural contexts are likely to have; culture-specific ones in experiences only people in specific cultures are likely to have.

Our results reveal culture-generalizability and culture-specificity. Regarding culturegeneralizability, our measures attain a reasonable degree of invariance. Given a universal need to make sense of difficulties in ways that promote both engagement and disengagement, we predicted that difficulty mindsets would be culturally general. Regarding culture-specificity, societies differ in how much people endorse each mindset and how much their endorsements covary. Culture-specific beliefs, traditions, and practices give people within a culture a way of thinking and engaging with their world (Boyd, 2017; Cosmides \& Tooby, 1992; Henrich, 2016; Oyserman, 2017). On average, WEIRD-er cultures are less conservative, religious, and spiritual and believe less in a just world and karma. We predicted that these beliefs would be associated 
with higher difficulty-as-improvement scores and hence predicted that people in less WEIRD cultures would score higher in difficulty-as-improvement.

\section{Culturally Specific Thinking Styles}

People in less-WEIRD cultures can hold in mind each way of interpreting difficulty. Therefore, how much they endorse one difficulty mindset has less effect on how much they endorse another (weaker correlations). People in WEIRD-er cultures tend to endorse either one way of interpreting difficulty or another (stronger correlations). Our results thus provide converging evidence that people in less-WEIRD cultures are more likely to engage in a "bothand" reasoning style and people in WEIRD-er ones are more likely to engage in an "either-or" reasoning style. Cultures vary in how much they socialize for individual vs. collective connections. These patterns of social cognition, we argue, carry over to thinking styles --to whether people consider ideas as conflicting or co-existing (Ji et al., 2001; Nisbett, 2004; Nisbett \& Miyamoto, 2005; Oyserman et al., 2009; Peng \& Nisbett, 1999; Talhelm et al., 2015). Our results expand prior studies examining cognitive processes to include less WEIRD societies not typically studied --India, Iran, and Turkey.

\section{Limitations and Future Directions}

Each set of studies is limited. Ours is no exception. We focus on three: sampling frame, methodology, and dependent variables as a bridge to other theories. Regarding the sampling frame, we included a range of societies, purposefully including people from societies that are less represented in psychological research and from diverse societies. Our measures showed measurement invariance and effect on identity across samples. These results increased our confidence that our theory is generalizable. But we did not draw random, representative samples, nor do these eight societies represent all human populations. Hence our results represent the first 
steps, requiring further replication in understudied populations. Our results are particularly preliminary for our analyses of the relationship between difficulty-as-improvement and culturebased blueprints for making sense of life suffering. Given the study we conducted, the strength of the relationship is likely society-specific, so adding a broader range of societies will help specify which aspects are culture-specific vs. culture-general.

Second, regarding our method, we document associations at a particular time. We show that these associations are culture-general and robust to accounting for the effects of difficultyas-importance and difficulty-as-impossibility. Future studies examining contextual effects could begin to assess the extent to which life difficulties increase interpretations of difficulty-asimprovement. Our computational linguistic methodology in Study 2 paves the way for future computational research to examine how these constructs change across historical time (see Atari \& Henrich, 2022).

Finally, regarding dependent variables, we chose four that prior research has tied to a resilient identity. Our results provide a basis for future studies expanding dependent variables in at least four ways. First, a venue for a future study is examining the effects of difficulty mindsets on choice, especially the preference for taking harder paths even when easier ones are available. Difficulty-as-impossibility may focus people on the easier path; difficulty-as-improvement may imply that the easy path is not to be taken. Instead, people who score higher in difficulty-asimprovement may prefer the hard way to attain goals as a carryover of their sense that experiencing unchosen life difficulties can be character-building.

Second, future research can examine under which circumstances people see difficulties as something to be endured (difficulty-as-improvement) rather than as choices (difficulty-asimportance). For example, while people can experience school tasks and goals as choices, they 
should also be able to consider them as things to be endured. And the reverse, it seems possible that depending on the context, people find almost any circumstance as having an element of choice. Where people chronically draw a line to distinguish between the two may be culturebased.

A third venue for future study is examining the connections between identity-based motivation and additional personality variables and culture-based blueprints to explain suffering. In the former group, for example, future work might consider narrative approaches to identity that focus on how people synthesize their identities from salient, key moments (e.g., turning points, self-defining memories; Dunlop et al. 2020; McAdams \& McLean, 2013; McLean et al., 2020). Narrative approaches define a sequence in which a positive event follows a negative one as redemptive (Adler et al., 2015; McAdams, 2013; McAdams et al., 2001). Connection with difficulty mindsets is possible because narrative identity scholars have recently developed a close-ended measure of what they describe as a redemptive mindset (e.g., "If I receive bad news, it tends to work out in the long run," Dunlop et al., 2020). It is possible that the redemptive mindset, which the authors describe as a general belief system tied to the Protestant Ethic, may be associated with our culture-general difficulty-as-improvement measure.

Fourth, regarding deviation from culture-based blueprints for how life should unfold, future work might consider other blueprints that fit in our deservingness and higher authority categories. For example, the prosperity gospel within the Pentecostal form of Christianity is present in African and North American regions. It could focus people on obtaining material rather than character gains through suffering (e.g., Heuser, 2016).

\section{Conclusion}


We used a culture-based approach to expand identity-based motivation theory to how people make sense of their life difficulties. We predicted and showed that difficulty-asimprovement is both culture-general — shared across cultures — and culture-specific, more likely to be endorsed in societies that are less Western, educated, industrialized, rich, or democratic. We developed a culturally general difficulty-as-improvement measure. We showed that people who score higher in difficulty-as-improvement tend to construct more resilient identities, seeing themselves as conscientious, virtuous, optimistic people living lives of meaning. In the face of difficulties, a difficulty-as-improvement mindset can provide the courage to keep going by offering hope, meaning, and the will to engage conscientiously and virtuously. 
DIFFICULTY-AS-IMPROVEMENT SUPPLEMENTAL MATERIALS 12

\section{References}

Adler, J., Turner, A., Brookshier, K., Monahan, C., Walder-Biesanz, I., Harmeling, L., Albaugh, M., McAdams, D., \& Oltmanns, T. (2015). Variation in narrative identity is associated with trajectories of mental health over several years. Journal of Personality and Social Psychology, 108(3), 476-496. https://doi.org/10.1037/a0038601

Aelenei, C., Lewis Jr, N., \& Oyserman, D. (2017). No pain no gain? Social demographic correlates and identity consequences of interpreting experienced difficulty as importance. Contemporary Educational Psychology, 48, 43-55. https://doi.org/10.1016/j.cedpsych.2016.08.004

Apicella, C., Norenzayan, A., \& Henrich, J. (2020). Beyond WEIRD: A review of the last decade and a look ahead to the global laboratory of the future. Evolution and Human Behavior, 41(5), 319-329. https://doi.org/10.1016/j.evolhumbehav.2020.07.015

Arthur, S. (2019). Contemporary religions in China. Routledge.

Atari, M., \& Henrich, J. (2022, June 30). Historical Psychology. https://doi.org/10.31234/osf.io/m8b9g

Atari, M., \& Dehghani, M. (2022). Language analysis in moral psychology. In M. Dehghani \& R. Boyd (Eds.), Handbook of language analysis in psychology (pp. 207-228). Guilford.

Azizi, F. (2010). Islamic fasting and health. Annals of Nutrition and Metabolism, 56(4), 273-282.

Bates, D., Mächler, M., Bolker, B., \& Walker, S. (2015). Fitting linear mixed-effects models using lme4. Journal of Statistical Software, 67(1), 1-48. https://doi.org/10.18637/jss.v067.i01

Berntsen, D. \& Rubin, D. (2004). Cultural life scripts structure recall from autobiographical memory. Memory \& Cognition, 32(3), 427-442 
Bojanowski, P., Grave, E., Joulin, A., \& Mikolov, T. (2017). Enriching word vectors with subword information. Transactions of the Association for Computational Linguistics, 5, 135-146. https://doi.org/10.1162/tacl a 00051

Bowker, J., \& Bowker, J. (1975). Problems of suffering in religions of the world. Cambridge University Press.

Boyd, R. (2017). A Different Kind of Animal: How Culture Transformed Our Species. Princeton. Britannica. (2020, May 28). Lent. In Encyclopedia Britannica. Retrieved 10-29-2021, from https://www.britannica.com/topic/Lent

Carney, D., Jost, J., Gosling, S., \& Potter, J. (2008). The secret lives of liberals and conservatives: Personality profiles, interaction styles, and the things they leave behind. Political Psychology, 29(6), 807-840. https://doi.org/10.1111/j.1467-9221.2008.00668.x

Chen, F., Curran, P. J., Bollen, K., Kirby, J., \& Paxton, P. (2008). An empirical evaluation of the use of fixed cutoff points in RMSEA test statistic in structural equation models. Sociological methods \& research, 36(4), 462-494.

Cheung, G., \& Rensvold, R. (2002). Evaluating goodness-of-fit indexes for testing measurement invariance. Structural Equation Modeling, 9(2), 233-255. https://doi.org/10.1207/s15328007sem0902_5

Chittick, W. (1983). The Sufi path of love: The spiritual teachings of Rumi. SUNY Press.

Cook, F. (1979). Who should be helped: public support for social services. Sage.

Cosmides, L., \& Tooby, J. (1992). Cognitive adaptations for social exchange. In J. Barkow (Ed.), The adapted mind (pp. 163-228). Oxford.

Dalai Lama. (1995). The Dalai Lama's book of wisdom. Thorsons.

Dunlop, W., Wilkinson, D., Harake, N., Graham, L., \& Lee, D. (2020). The redemption and 
contamination research form: exploring relations with narrative identity, personality traits, response styles, and life satisfaction. Memory, 28(10), 1219-1230.

Dweck, C., Chiu, C.-Y., \& Hong, Y.-Y. (1995). Implicit theories and their role in judgments and reactions: A word from two perspectives. Psychological Inquiry, 6(4), 267-285. https://doi.org/10.1207/s15327965pli0604_1

Eisner, J. (2014). The origins of explanatory style: Trust as a determinant of optimism and pessimism. Explanatory Style, 1, 59-66.

Ek, E., Remes, J., \& Sovio, U. (2004). Social and developmental predictors of optimism from infancy to early adulthood. Social Indicators Research, 69(2), 219-242.

Ellemers, N., van der Toorn, J., Paunov, Y., \& van Leeuwen, T. (2019). The psychology of morality: A review and analysis of empirical studies published from 1940 through 2017. Personality and Social Psychology Review, 23(4), 332-366.

Everly, G., McCormack, D., \& Strouse, D. (2012). Seven characteristics of highly resilient people: Insights from Navy SEALs to the 'Greatest Generation'. International Journal of Emergency Mental Health, 14(2), 137-143.

Feather, N. (1984). Protestant Ethic, conservatism, and values. Journal of Personality and Social Psychology, 46(5), 1132-1141.

Feather, N. (1992). An attributional and value analysis of deservingness in success and failure situations. British Journal of Social Psychology, 31(2), 125-145.

Fisher, O., \& Oyserman, D. (2017). Assessing Interpretations of Experienced Ease and Difficulty as Motivational Constructs. Motivation Science, 3(2), 133-163. https://doi.org/10.1037/mot0000055

Frankl, V. (1946). Man's search for meaning. Beacon Press. 
Furnham, A. (1993). Just world beliefs in twelve societies. The Journal of Social Psychology, 133(3), 317-329.

Furnham, A., \& Bland, C. (1983). The Protestant work ethic and conservatism. Personality and Individual Differences, (4)2, 205-206.

Furnham, A., \& Gunter, B. (1984). Just world beliefs and attitudes towards the poor. British Journal of Social Psychology, 23(3), 265-269.

Gelfand, M., \& Jackson, J. (2016). From one mind to many: The emerging science of cultural norms. Current Opinion in Psychology, 8, 175-181.

Graham, J., Haidt, J., \& Nosek, B. (2009). Liberals and conservatives rely on different sets of moral foundations. Journal of Personality and Social Psychology, 96(5), 1029-1046

Gray, K., \& Wegner, D. (2010). Blaming God for our pain: Human suffering and the divine mind. Personality and Social Psychology Review, 14(1), 7-16.

Greeff, A. P., \& Ritman, I. N. (2005). Individual characteristics associated with resilience in single-parent families. Psychological Reports, 96(1), 36-42.

Haidt, J. (2012). The righteous mind: Why good people are divided by politics and religion. Knopf Doubleday.

Hansen, K. (2019). Who cares if they need help? The deservingness heuristic, humanitarianism, and welfare opinions. Political Psychology, 40(2), 413-430.

Harvey, P. (2012). An introduction to Buddhism: Teachings, history and practices. Cambridge University Press.

Henrich, J. (2016). The secret of our success: How culture is driving human evolution, domesticating our species, and making us smarter. Princeton.

Henrich, J. (2020). The WEIRDest people in the world: How the West became psychologically 
peculiar and particularly prosperous. Penguin UK.

Henrich, J., Heine, S., \& Norenzayan, A. (2010). The weirdest people in the world? Behavioral and Brain Sciences, 33(2-3), 61-83.

Herman, A. (2018). A brief introduction to Hinduism: Religion, philosophy, and ways of liberation. Routledge.

Heuser, A. (2016). Charting African prosperity gospel economies. HTS: Theological Studies, 72(4), 1-9.

Hjelle, L., Busch, E., \& Warren, J. (1996). Explanatory style, dispositional optimism, and reported parental behavior. The Journal of Genetic Psychology, 157(4), 489-499.

Ivtzan, I., Chan, C, Gardner, H., \& Prashar, K. (2013). Linking religion and spirituality with psychological well-being: Examining self-actualisation, meaning in life, and personal growth initiative. Journal of Religion and Health, 52(3), 915-929.

Ji, L. J., Nisbett, R., \& Su, Y. (2001). Culture, change, and prediction. Psychological Science, 12(6), 450-456.

John, O. \& Srivastava, S. (1999). The Big Five trait taxonomy: History, measurement, and theoretical perspectives. In L. Pervin \& O. John (Eds.), Handbook of Personality: Theory and Research, $2^{\text {nd }}$ ed., pp. 102-138. Guilford.

Jonas, E., \& Fischer, P. (2006). Terror management and religion: evidence that intrinsic religiousness mitigates worldview defense following mortality salience. Journal of Personality and Social Psychology, 91(3), 553-567.

Jorgensen, T., Pornprasertmanit, S., Schoemann, A., \& Rosseel, Y. (2021). semTools: Useful tools for structural equation modeling. R package version $0.5-5$. https://CRAN.Rproject.org $/$ package $=$ semTools 
Jost, J., \& Banaji, M. (1994). The role of stereotyping in system-justification and the production of false consciousness. British Journal of Social Psychology, 33(1), 1-27.

Jost, J., Banaji, M., \& Nosek, B. (2004). A decade of system justification theory: Accumulated evidence of conscious and unconscious bolstering of the status quo. Political Psychology, 25(6), 881-919.

Jost, J., Pelham, B., Sheldon, O., \& Ni Sullivan, B. (2003). Social inequality and the reduction of ideological dissonance on behalf of the system: Evidence of enhanced system justification among the disadvantaged. European Journal of Social Psychology, 33(1), 13-36.

Katz, M. (1989). The undeserving poor: From the war on poverty to the war on welfare. Pantheon.

Koenig, H., \& Büssing, A. (2010). The Duke University Religion Index (DUREL): A five-item measure for use in epidemiological studies. Religions, 1(1), 78-85.

Lecic-Tosevski, D., Vukovic, O., \& Stepanovic, J. (2011). Stress and personality. Psychiatriki, 22(4), 290-297.

Lipkus, I., Dalbert, C., \& Siegler, I. (1996). The importance of distinguishing the belief in a just world for self versus for others: Implications for psychological well-being. Personality and Social Psychology Bulletin, 22(7), 666-677. https://doi.org/10.1177/0146167296227002

Lupfer, M., \& Gingrich, B. (1999). When bad (good) things happen to good (bad) people: The impact of character appraisal and perceived controllability on judgments of deservingness. Social Justice Research, 12(3), 165-188.

Lupke, C. (2005). The magnitude of Ming: command, allotment, and fate in Chinese culture. 
University of Hawaii Press.

Massicotte, S (2012). A resilient identity. In B. Maisha, S. Massicotte, \& M. Morin (Eds.). Fostering resilience before, during, and after experiences of trauma: insights to inform practice across the lifetime. pp. 95-110. Routledge. https://doi.org/10.4324/9781003150855

Martela, F., Ryan, R., \& Steger, M. (2018). meaningfulness as satisfaction of autonomy, competence, relatedness, and beneficence: comparing the four satisfactions and positive affect as predictors of meaning in life. Journal of Happiness Studies, 19(5), 1261-1282. https://doi.org/10.1007/s10902-017-9869-7

McAdams, D. (2013). The redemptive self: Stories Americans live by (2nd ed.). Oxford University Press.

McAdams, D., \& McLean, K. (2013). Narrative identity. Current Directions in Psychological Science, 22(3), 233-238. https://doi.org/10.1177/0963721413475622

McAdams, D., Reynolds, J., Lewis, M., Patten, A., \& Bowman, P. (2001). When bad things turn good and good things turn bad: Sequences of redemption and contamination in life narrative and their relation to psychosocial adaptation in midlife adults and in students. Personality and Social Psychology Bulletin, 27(4), 474-485. https://doi.org/10.1177/0146167201274008

McGrath, R. (2019). Technical report: The VIA assessment suite for adults: Development and initial evaluation (rev ed.). Cincinnati, OH: VIA Institute on Character.

McLean, K., Syed, M., Pasupathi, M., Adler, J., Dunlop, W., Drustrup, D., ... \& McCoy, T. (2020). The empirical structure of narrative identity: The initial Big Three. Journal of Personality and Social Psychology, 119(4), 920. 
Mikolov, T., Sutskever, I., Chen, K., Corrado, G., \& Dean, J. (2013). Distributed representations of words and phrases and their compositionality. In C. Burges, L. Bottou, M. Welling, Z. Ghahramani \& K Weinberger (Eds). Advances in Neural Information Processing Systems, 26, pp. 3111-3119. ISBN: 9781632660244

Muki, A. (2021). Values upheld within peer culture and resilient identity among mid adolescents (15-17 years Old) in Mbengwi Sub Division. Central Asian Journal of Social Sciences and History, 2(1), 1-9.

New International Version Bible. (2011). The NIV Bible. https://www.thenivbible.com.

Newman, D., Schwarz, N., Graham, J., \& Stone, A. (2018). Conservatives report greater meaning in life than liberals. Social Psychological and Personality Science, 10(4), 494503. https://doi.org/10.1177/1948550618768241

Nisbett, R. (2004). The geography of thought: How Asians and Westerners think differently... and why. Simon and Schuster.

Nisbett, R., \& Miyamoto, Y. (2005). The influence of culture: holistic versus analytic perception. Trends in cognitive sciences, 9(10), 467-473.

O’Donnell, S., Yan, V. X., Bi, C., \& Oyserman, D. (2022). Is difficulty mostly about impossibility? What difficulty implies may be culturally variant. Personality and Social Psychology Bulletin. https://doi.org/10.1177/01461672211065595

Oyserman, D. (2007). Social identity and self-regulation. In A. Kruglanski \& T. Higgins (Eds.), Handbook of Social Psychology (2nd ed., pp. 432-453). Guilford.

Oyserman, D. (2009). Identity-based motivation: Implications for action-readiness, proceduralreadiness, and consumer behavior. Journal of Consumer Psychology, 19, 250-260. https://doi.org/10.1016/j.jcps.2009.05.008 
Oyserman, D. (2015). Identity-based motivation. Emerging trends in the social and behavioral sciences: An interdisciplinary, searchable, and linkable resource, 1-11. https://doi.org/10.1002/9781118900772.etrds0171

Oyserman, D. (2017). Culture three ways: Culture and subcultures within countries. Annual Review of Psychology, 68, 435-463. https://doi.org/10.1146/annurev-psych-122414$\underline{033617}$

Oyserman, D., Coon, H., \& Kemmelmeier, M. (2002). Rethinking individualism and collectivism: Evaluation of theoretical assumptions and meta-analyses. Psychological Bulletin, 128, 3-73.

Oyserman, D., Destin, M., \& Novin, S. (2015). The context-sensitive future self: Possible selves motivate in context, not otherwise. Self and identity, 14(2), 173-188.

Oyserman, D., Elmore, K., Novin, S., Fisher, O., \& Smith, G. (2018). Guiding people to interpret their experienced difficulty as importance highlights their academic possibilities and improves their academic performance. Frontiers in Psychology, 9, Article 781. https://doi.org/10.3389/fpsyg.2018.00781

Oyserman, D., Elmore, K., \& Smith, G. (2012). Self, self-concept, and identity. In M. Leary \& J. Tangney (Eds.), Handbook of Self and Identity (pp. 69-104). Guilford.

Oyserman, D., Fryberg, S., \& Yoder, N. (2007). Identity-based motivation and health. Journal of Personality and Social Psychology, 93(6), 1011-1027. https://doi.org/10.1037/0022$\underline{3514.93 .6 .1011}$

Oyserman, D., Lewis Jr, N., Yan, V. X., Fisher, O., O'Donnell, S., \& Horowitz, E. (2017). An identity-based motivation framework for self-regulation. Psychological Inquiry, 28(2-3), 139-147. https://doi.org/10.1080/1047840X.2017.1337406 
Oyserman, D., O'Donnell, S., Sorensen, N., \& Wingert, K. (2021). Process matters: Teachers benefit their classrooms and students when they deliver an identity-based motivation intervention with fidelity. Contemporary Educational Psychology, 66, 101993.

Oyserman, D., Sorensen, N., Reber, R., \& Chen, S. (2009). Connecting and separating mind-sets: Culture as situated cognition. Journal of Personality and Social Psychology, 97(2), 217235.

Oyserman, D., \& Yan, V. X. (2019). Making meaning: a culture-as-situated cognition approach to the consequences of cultural fluency and disfluency. In D. Cohen \& S. Kitayama (Eds.) Handbook of Cultural Psychology, Vol 2, 536-565. Guilford.

Peng, K., \& Nisbett, R. (1999). Culture, dialectics, and reasoning about contradiction. The American Psychologist, 54(9), 741-754. https://doi.org/10.1037/0003-066X.54.9.741

Pew Research Center. (2018). The Age Gap in Religion Around the World. https://www.pewresearch.org/religion/2018/06/13/how-religious-commitment-varies-bycountry-among-people-of-all-ages/

R Core Team (2019). R: A language and environment for statistical computing. R Foundation for Statistical Computing, Vienna, Austria. https://www.R-project.org/

Rad, M., Martingano, A., \& Ginges, J. (2018). Toward a psychology of Homo sapiens: Making psychological science more representative of the human population. Proceedings of the National Academy of Sciences, 115(45), 11401-11405.

\section{https://doi.org/10.1073/pnas.1721165115}

Rai, T. \& Fiske, A. (2011). Moral psychology is relationship regulation: Moral motives for unity, hierarchy, equality, and proportionality. Psychological Review, 118(1), 57-75. https://doi.org/10.1037/a0021867 
Rasinski, K. (1987). What's fair is fair-Or is it? Value differences underlying public views about social justice. Journal of Personality and Social Psychology, 53(1), 201-211. https://doi.org/10.1037/0022-3514.53.1.201

Revelle, W. (2021). psych: Procedures for Psychological, Psychometric, and Personality Research. Northwestern University, Evanston, Illinois. R package version 2.1.9, https://CRAN.R-project.org/package=psych

Reynolds, C., Makhanova, A., Ng, B., \& Conway, P. (2020). Bound together for God and country: The binding moral foundations link unreflectiveness with religiosity and political conservatism. Personality and Individual Differences, 155, 109632. https://doi.org/10.1016/j.paid.2019.109632

Rosseel, Y. (2012). Lavaan: An R package for structural equation modeling and more. Version 0.5-12 (BETA). Journal of Statistical Software, 48(2), 1-36.

Scheier, M., Carver, C., \& Bridges, M. (1994). Distinguishing optimism from neuroticism (and trait anxiety, self-mastery, and self-esteem): a reevaluation of the Life Orientation Test. Journal of Personality and Social Psychology, 67(6), 1063-1078.

Schwartz, M. (1983). The meaning of suffering: a Talmudic response to theodicy. Judaism, $32(4), 444-451$.

Sengupta, N., Osborne, D., \& Sibley, C. (2015). The status-legitimacy hypothesis revisited: Ethnic-group differences in general and dimension-specific legitimacy. British Journal of Social Psychology, 54(2), 324-340. https://doi.org/10.1111/bjso.12080

Singh, S. (2022). Self and suffering in Indian thought: implications for clinicians. BJPsych Advances, 1-11.

Skitka, L., \& Tetlock, P. (1993). Providing public assistance: Cognitive and motivational 
DIFFICULTY-AS-IMPROVEMENT SUPPLEMENTAL MATERIALS 23

processes underlying liberal and conservative policy preferences. Journal of Personality and Social Psychology, 65(6), 1205-1223. https://doi.org/10.1037/0022-3514.65.6.1205

Skurka, C., Winett, L., Jarman-Miller, H., \& Niederdeppe, J. (2020). All things being equal: Distinguishing proportionality and equity in moral reasoning. Social Psychological and Personality Science, 11(3), 374-387. https://doi.org/10.1177/1948550619862261

Smith, G. \& Oyserman, D. (2015) Just not worth my time? Experienced difficulty and time investment. Social Cognition, 33, 85-103. https://doi.org/10.1521/soco.2015.33.2.1

Stankov, L. (2017). Conservative syndrome: Individual and cross-cultural differences. Journal of Cross-Cultural Psychology, 48(6), 950-960. https://doi.org/10.1177/0022022117709984

Steger, M., Frazier, P., Oishi, S., \& Kaler, M. (2006). The meaning in life questionnaire: Assessing the presence of and search for meaning in life. Journal of Counseling Psychology, 53(1), 80-93. https://doi.org/10.1037/0022-0167.53.1.80

Talhelm, T. (2020). Emerging evidence of cultural differences linked to rice versus wheat agriculture. Current Opinion in Psychology, 32, 81-88.

Talhelm, T., Haidt, J., Oishi, S., Zhang, X., Miao, F., \& Chen, S. (2015). Liberals think more analytically (more "WEIRD”) than conservatives. Personality and Social Psychology Bulletin, 41(2), 250-267.

Taş, I., \& İskender, M. (2018). An examination of meaning in life, satisfaction with life, selfconcept and locus of control among teachers. Journal of Education and Training Studies, $6(1), 21-31$.

Thrane, S. (2010). Hindu end of life: Death, dying, suffering, and karma. Journal of Hospice \& Palliative Nursing, 12(6), 337-342.

Wakslak, C., Jost, J., Tyler, T., \& Chen, E. (2007). Moral outrage mediates the dampening effect 
of system justification on support for redistributive social policies. Psychological Science, 18(3), 267-274. https://doi.org/10.1111/j.1467-9280.2007.01887.x

White, C., \& Norenzayan, A. (2019). Belief in karma: How cultural evolution, cognition, and motivations shape belief in supernatural justice. Advances in Experimental Social Psychology, 60, 1-63.

White, C., Norenzayan, A., \& Schaller, M. (2019). The content and correlates of belief in Karma across cultures. Personality and Social Psychology Bulletin, 45(8), 1184-1201. https://doi.org/10.1177/0146167218808502

Whitman, S. (2007). Pain and suffering as viewed by the Hindu religion. The Journal of Pain, 8(8), 607-613.

Yan, V. X., \& Oyserman, D. (2018). The world as we see it: The culture-identity-metacognition interface. J. Proust \& M. Fortier (Eds). Metacognitive Diversity: An Interdisciplinary Approach (pp, 225-244). Oxford. https://doi.org/10.1093/oso/9780198789710.003.0011

Yao, X., \& Badham, P. (2007). Religious experience in contemporary China. University of Wales Press. 


\section{Supplemental Materials}

\section{Difficulty-as-Improvement Condition}

\section{Study 1 Materials}

After reading the prompt (reported in the body of the paper) participants were shown the following:

Imagine you are part of this culture.

Think about its difficulty-as-improvement lens. Think about a life difficulty you recently experienced or are currently experiencing and how you used (or could use) a difficulty-asimprovement lens to experience this life difficulty as a path to self-improve, mature, and build character.

In a few words, describe the life difficulty you are thinking about:

[essay box]

Describe how it helped you or could help you improve, mature, and build character:

[essay box]

\section{Difficulty-as-Importance Condition}

This first task focuses on cultural awareness. One aspect of cultural awareness is how people from different cultural backgrounds think about difficulty.

To do this task, you will be asked to immerse yourself in a specific culture's way of thinking about difficulty.

Please imagine that you are living in a culture where people see difficulty with a task or goal as a signal of its value and worth. People who are part of this culture believe that difficulties are there for a reason. Difficulties may not be pleasant but they serve a purpose. They signal to you that the goal or task you are working on is worthwhile for you, something that is important for you to succeed at. When a task or goal is difficult, it means that it is for you and worth your while to effortfully engage in. People in this culture accept difficulties for what they are-signals of task value and worth.

Imagine you are part of this culture.

Think about its difficulty-as-value lens. Think about a difficulty you recently experienced while engaging with a task or goal or are currently experiencing and how you used (or could use) a difficulty-as-value lens to remind you that difficulty can be a signal that the task or goal is important for you.

In a few words, describe the task or goal you are thinking of:

[essay box] 
Describe how experiencing difficulty with the task or goal helped (or could help) you see the importance and value for yourself in succeeding at that task or attaining that goal:

[essay box]

\section{Difficulty-as-Impossibility Condition}

This first task focuses on cultural awareness. One aspect of cultural awareness is how people from different cultural backgrounds think about difficulty.

To do this task, you will be asked to immerse yourself in a specific culture's way of thinking about difficulty. Take your time with this task. The arrow to continue to the next page will appear after two minutes to ensure that you spend enough time with this task.

Please imagine that you are living in a culture where people see difficulty with a task or goal as a signal that they should switch to something else. People who are part of this culture believe that difficulties are there for a reason. Difficulties may not be pleasant but they serve a purpose. They signal to you that the goal or task you are working on may not be worthwhile for you, something that may not be worth spending time on. When a task or goal is difficult, it means that you may be better off switching to something else. People in this culture accept task difficulties for what they are-signals that you should focus on something else instead.

Imagine you are part of this culture.

Think about its difficulty-means-switch lens. Think about a difficulty you recently experienced while engaging in a task or goal or are currently experiencing and how you used (or could use) a difficulty-means-switch lens to remind you that difficulty can be a signal that the task or goal is not worth your while and your efforts are better spent elsewhere.

In a few words, describe the task or goal you switched out of:

[essay box]

Describe how experiencing difficulty with the task or goal helped (or could help) you see that you might be better off switching out of that goal or task and thus save your efforts:

[essay box]

\section{Control Condition}

This first task focuses on cultural awareness. One aspect of cultural awareness is how people from different cultural backgrounds think.

This exercise focuses on immersing yourself in a different culture's way of thinking. Your responses will help us develop materials for future students.

Please imagine that you live in a culture where people see the world differently than you do. People who are part of this culture believe things that are different from your own beliefs. Immerse yourself in that experience. Think of some ways that this culture might be similar to the way you are now. Think of some ways that this culture might be different from the way you are now. 
Imagine you are part of this culture.

Think about an experience you recently had and how it might have occurred differently if you lived in this different culture.

In a few words, describe the recent experience you are thinking of: [essay box]

Describe how this experience could have been different if you lived in this different culture: [essay box] 
DIFFICULTY-AS-IMPROVEMENT SUPPLEMENTAL MATERIALS 28

Study 2 Materials

\section{Table S1}

Study 1 Seed Word Sets: Synonyms of Difficulty, Difficulty Variants, Synonyms of Importance, Synonyms of Impossibility, Synonyms of Improvement, and a Random Word Set

\begin{tabular}{llllll}
\hline Difficulty & Difficulty (max baseline) & Importance & Impossibility & Improvement & Random (min baseline) \\
\hline difficulty & difficulties & important & impossible & self-improvement & banana \\
challenge & challenging & rewarding & unachievable & self-discipline & word \\
complication & complicated & informative & unattainable & better & gray \\
misery & complications & pivotal & unworkable & maximize & infrastructure \\
difficult & hard & importance & impossibility & improvement & sky \\
hindrance & impediment & reward & pointless & character-building & psychology \\
hurdle & troublesome & critical & inability & improve & tower \\
suffering & hardships & invaluable & incapable & transcend & salt \\
hardship & suffer & worthy & unlikely & develop & Atlanta \\
trouble & burdens & vitally & infeasible & strengthen & hotel \\
strain & tough & imperative & hopeless & elevate & timber \\
laborious & sufferings & beneficial & unreachable & self-control & commission \\
adversity & efforts & valuable & fail & enhance & computer \\
burden & suffers & worthwhile & insurmountable & promote & pizza \\
effort & hinder & vital & cannot & self-growth & random \\
\hline
\end{tabular}




\section{Studies 3-15 Measures}

\section{Table S2}

Studies 3-13: Mean and Standard Deviation of Difficulty Mindsets and Outcome Measures by Society

\begin{tabular}{|c|c|c|c|c|c|c|c|}
\hline & \multicolumn{7}{|c|}{ Mean (SD) by society } \\
\hline & Australia & Canada & China & Iran & New Zealand & Turkey & The U.S. \\
\hline \multicolumn{8}{|l|}{ Difficulty Mindsets } \\
\hline Difficulty-as-Importance & $3.93(0.85)$ & $4.10(0.89)$ & $3.99(1.01)$ & $3.89(0.93)$ & $3.96(0.89)$ & $4.04(1.13)$ & $4.13(0.84)$ \\
\hline Difficulty-as-Impossibility & $3.33(1.00)$ & $3.20(1.12)$ & $3.10(0.97)$ & $2.23(0.82)$ & $3.11(1.05)$ & $2.40(1.12)$ & $3.04(1.08)$ \\
\hline \multicolumn{8}{|c|}{ Identity Construction Measures } \\
\hline Meaning in Life & $3.62(1.19)$ & $3.82(1.24)$ & $4.10(0.93)$ & $4.61(1.00)$ & $3.45(1.21)$ & $4.55(1.15)$ & $3.95(1.09)$ \\
\hline Optimism & $3.65(1.00)$ & $3.69(1.02)$ & $4.11(0.76)$ & $4.12(0.83)$ & $3.54(1.06)$ & $4.40(0.90)$ & $3.72(1.02)$ \\
\hline Conscientiousness & $4.13(0.79)$ & $4.29(0.82)$ & $4.29(0.61)$ & $4.35(0.71)$ & $4.18(0.80)$ & $4.79(0.84)$ & $4.36(0.76)$ \\
\hline Virtues & $4.23(0.65)$ & $4.41(0.64)$ & $4.39(0.73)$ & $4.34(0.73)$ & $4.17(0.70)$ & $4.55(0.92)$ & $4.43(0.66)$ \\
\hline
\end{tabular}

Note. In each more-WEIRD society (Australia, Canada, New Zealand, the US), identity construction measures were assessed in two separate studies for each society-meaning in life and optimism were assessed in Studies 2 to 5, and conscientiousness and virtues were assessed in Studies 6 to 9. Difficulty mindsets were assessed in all studies. To increase the stability of estimates, the alpha reliabilities for difficulty-as-importance and difficulty-as-impossibility in more-WEIRD societies are shown for aggregated datasets (Australia $N=270$, Canada $N=270$, New Zealand $N=270$, the U.S. $N=404$ ). 
DIFFICULTY-AS-IMPROVEMENT SUPPLEMENTAL MATERIALS 30

\section{Table S4}

Identity-construction Scale Items

\begin{tabular}{|c|c|}
\hline Scale & Instruction Prompt \\
\hline $\begin{array}{l}\text { Meaning in Life } \\
\text { (Steger et al., 2006) }\end{array}$ & $\begin{array}{l}\text { Below is a list of statements. Please read } \\
\text { each one and rate how much you agree or } \\
\text { disagree with the statement as it reflects } \\
\text { your life until now. There are no right or } \\
\text { wrong answers. We are not interested in } \\
\text { what you think most people would answer, } \\
\text { but rather in how you feel about your own } \\
\text { experiences. }\end{array}$ \\
\hline
\end{tabular}

Optimism LOT-R

(Scheier et al., 1994)

Below is a list of statements. Please read each one and rate how much you agree or disagree with the statement as it reflects your life until now. There are no right or wrong answers. We are not interested in what you think most people would answer, but rather in how you feel about your own experiences.

Conscientiousness (Big Five Inventory, John \& Srivastava, 1999)

\section{Items}

1. I understand my life's meaning.

2. My life has a clear sense of purpose.

3. I have a good sense of what makes my life meaningful.

4. I have discovered a satisfying life purpose.

5. My life has no clear purpose.

1. In uncertain times, I usually expect the best.

2. If something can go wrong for me, it will. (R)

3. I'm always optimistic about my future.

4. I hardly ever expect things to go my way. (R)

5. I rarely count on good things happening to me. (R)

6. Overall, I expect more good things to happen to me than bad. ${ }^{\mathrm{a}}$

1. I do a thorough job.

2. I can be somewhat careless. (R)

3. I am a reliable worker.

4. I tend to be disorganized. (R)

5. I tend to be lazy. (R)

6. I persevere until the task is finished.

7. I do things efficiently.

8. I make plans and follow through with them.

9. I am easily distracted. (R) in how you would describe yourself until now. 
Virtues

(Modified from

GACS-24; McGrath,

2017)
Below is a list of characteristics that may or may not apply to you. The definition of each characteristic is given. Please read each one and rate how natural and effortless it has been for you to express this characteristic so far in your life. Only you can judge what has been true for you in your own life. There are no right or wrong answers. Please answer according to your own personal experiences, rather than what you think most people would answer.
1. Judgment/Critical Thinking: Being analytical; examining things from all sides; not jumping to conclusions, but instead attempting to weigh all the evidence when making decisions. It is natural and effortless for me to use Judgment and Critical Thinking.

2. Perseverance: To keep going and going when you have a goal in mind; attempting to overcome all obstacles; finishing what you start. It is natural and effortless for me to Persevere.

3. Prudence: Being wisely cautious, planful and conscientious; careful to not take undue risks or do things you might later regret. It is natural and effortless for me to be Prudent.

4. Self-Regulation: Being a very disciplined person; managing your vices and bad habits; staying calm and cool under pressure; managing your impulses and emotions. It is natural and effortless for me to SelfRegulate.

5. Love: Being warm and genuine to others; sharing and being open to receiving love from others; valuing growing close and intimate with others. It is natural and effortless for me to express and receive Love.

6. Kindness: Doing good things for people; helping and caring for others; being generous, giving and compassionate. It is natural and effortless for me to be Kind.

7. Forgiveness/Mercy: Readily letting go of hurt after you are wronged; giving people a second chance; not being vengeful or resentful; accepting people's shortcomings. It is natural and effortless for me to express Forgiveness and Mercy.

8. Gratitude: Regularly experiencing and expressing thankfulness; not taking the good things that happen in your life for granted; tending to feel blessed in many circumstances. It is natural and effortless for me to feel Gratitude.

Note. Response options were 1=strongly disagree to 6=strongly agree. To create a brief 8-item character virtues scale, we selected eight virtues from the 24-item Global Assessment of Character Strengths (McGrath, 2017). McGrath and colleagues concluded a 3 factor structure (caring, self-control, inquisitiveness) as the most parsimonious and appropriate way to conceptualize the 24 virtues (McGrath, 2015; McGrath et al., 2018). We focused on self-control and caring, based on our theory, choosing four items that loaded strongly on each factor (McGrath, 2015) and were relevant to difficulty mindsets-for self-control (self-regulation, prudence,

perseverance, and judgment/critical thinking), for caring (love, gratitude, kindness, and forgiveness).

${ }^{\text {a }}$ Optimism Item 6 was inadvertently excluded from Studies 2 to 5 and 10. 


\section{Table S5}

Cultural Frame Scales

\section{Construct (Source) Items}

Karma Beliefs

(White et al., 2019)

Just World Beliefs

(Lipkus, et al., 1996)
Spirituality

(Adapted from White et al., 2019; Koenig

\& Büssing, 2010)

Religiosity (Adapted from White et al., 2019; Koenig \& Büssing, 2010)

Conservatism (Newman et al., 2018)
1. When people are met with misfortune, they have brought it upon themselves by their previous behavior.

2. When people experience good fortune, they have brought it upon themselves by their previous behavior.

3. If a person does something bad, even if there are no immediate consequences, they will be punished for it in some future time.

4. When someone does a good deed, even if there are no immediate consequences, they will be rewarded for it in some future time.

5. In the long-run, good things happen to good people and bad things happen to bad people.

1. The world treats me fairly.

2. I get what I deserve.

3. People treat me fairly in life.

4. I earn the rewards and punishments I get.

5. People treat me with the respect I deserve.

6. I get what I am entitled to have.

7. My efforts are noticed and rewarded.

8. When I meet with misfortune, I have brought it upon myself.

1. I am a spiritual person.

2. My spiritual beliefs structure my approach to life.

3. I try to carry my spiritual beliefs into every aspect of my life.

4. I believe in a Higher Power/Universal Intelligence.

1. I am a religious person.

2. My religious beliefs structure my approach to life.

3. In my life, I experience the presence of the Divine (e.g., God or gods).

1. In general, how liberal or conservative are your political views?

2. In general, how liberal or conservative are you on social issues?

Note. The instructions for the karma and just world belief scales were: "Please read each of the following statements. Consider your life and the world around you and rate how much you agree or disagree (1=strongly disagree to $6=$ strongly agree) with each. We want to know about your experiences, not what you think most people would answer." Religiosity response options $(1=n o t$ at all religious to $7=$ very religious; for Spirituality ( $1=$ not at all spiritual to $7=$ very spiritual; Conservatism (1=very liberal to $7=$ very conservative $)$. 
DIFFICULTY-AS-IMPROVEMENT SUPPLEMENTAL MATERIALS 33

\section{Table S6}

Studies 13-14: Mean and Standard Deviation of Cultural Frame Measures by Society

\begin{tabular}{lcc}
\hline & \multicolumn{2}{c}{ Mean (SD) by Society } \\
\cline { 2 - 3 } Deservingness Frames & India & The U.S. \\
$\quad$ Karma & $4.51(0.86)$ & $3.36(0.95)$ \\
$\quad$ Belief in Just World & $4.48(0.72)$ & $3.72(0.75)$ \\
Authority Frames & & \\
$\quad$ Religiosity & $4.49(1.15)$ & $2.85(1.58)$ \\
$\quad$ Spirituality & $4.62(0.99)$ & $3.32(1.54)$ \\
$\quad$ Conservatism & $3.58(1.32)$ & $2.66(1.24)$ \\
\hline
\end{tabular}




\section{Confirmatory Factor Analysis of Cultural Frame Measures}

We ran one and two-factor confirmatory factor analyses to test if karma and just world beliefs were best understood as one or two factors and if religiosity and spirituality were best understood as one or two factors. As Table S7 shows, each set was best considered two factors rather than one; the CFI, TLI, AIC, and BIC values for each set indicated a better fit for the twofactor compared to the one-factor model. Hence, in our analyses, we use five possible culturebased frames (karma, just world, religiosity, spirituality, and conservatism).

Table S7

Confirmatory Factor Analyses of Cultural Frames

\begin{tabular}{lcccccccc}
\hline Variables & Model & CFI & TLI & AIC & BIC & $\chi^{2}$ & $d f$ & $p$ \\
\hline $\begin{array}{l}\text { Karma and Just } \\
\text { World Beliefs }\end{array}$ & 1-factor & .750 & .699 & 23500.87 & 23617.40 & 1276.20 & 65 & \\
& 2-factor & .831 & .795 & 23105.92 & 23226.92 & 879.25 & 64 & $<.001$ \\
\hline & 1-factor & .949 & .924 & 12741.82 & 12804.58 & 274.16 & 14 & \\
$\begin{array}{l}\text { Religiosity and } \\
\text { Spirituality }\end{array}$ & 2-factor & .962 & .938 & 12679.11 & 12746.36 & 209.45 & 13 & $<.001$ \\
\end{tabular}

Note. $p$-values reflect the significance of the difference between $\chi^{2}$ values of the two models. 
DIFFICULTY-AS-IMPROVEMENT SUPPLEMENTAL MATERIALS 35

\section{H2 Supplemental Analyses and Results: Measurement Invariance of Difficulty Mindsets Across Societies}

To assess whether we can meaningfully compare difficulty mindsets across countries, we ran measurement invariance analyses. With invariance testing, researchers try to assess whether an instrument has the same measurement properties in two or more populations. It is important to identify whether model parameters are equivalent across populations, to rule out the possibility that individuals with the same level of the underlying factor have a different probability of giving a certain response to a specific item depending on the group that they belong to (Fischer \& Karl, 2019).

There are at least three different levels of invariance or equivalence that are often differentiated in the literature. The most basic level of measurement invariance is configural invariance, which tests whether the same item is associated with the same latent factor in each group. If found, it establishes that the same structure holds across groups (Chen, 2008). The second level of invariance is factor loading or metric invariance, which tests whether factor loadings are equal across groups. If this condition is met for all items and all groups, we can compare correlations and patterns of means (e.g., profiles) across groups (Fischer \& Karl, 2019). The third level of invariance is intercept or scalar invariance, which tests whether an item has the same point of origin across different groups. When invariance is achieved at both the factor loading and intercept levels, scores from different groups have the same unit of measurement (i.e., factor loading) as well as the same origin (i.e., intercept), and thus factor means can be compared across groups. Otherwise, it is not certain whether group differences on factor means are attributable to true group differences or to measurement artifacts (e.g., patterns of responding to particular items; Chen, 2008). The fourth level is the invariance of residual variance, which tests equivalence of residual variance across groups (Chen, 2008).

We used R packages lavaan (v. 0.6; Rosseel, 2012) and semTools (v. 0.5-5; Jorgensen et al., 2021) to test measurement invariance. To ascertain whether we can make meaningful crosscultural comparisons of difficulty mindsets, we fit four increasingly restricted CFA models. To handle the non-normality of our data, we used maximum likelihood estimation with robust standard errors and test statistics (MLR). With MLR, we retain our maximum likelihood point estimates, but we rescale the test statistic, standard errors, and fit indices to account for the violation of model assumptions.

To test difficulty-as-improvement, we used data from the eight societies in which we assessed difficulty-as-improvement (Australia, Canada, China, India, Iran, New Zealand, Turkey, and the United States). For difficulty-as-importance and difficulty-as-impossibility, we used data from seven societies in our dataset (Australia, Canada, China, Iran, New Zealand, Turkey, and the United States) in addition to data reported in O'Donnell and colleagues (2022) collected from China, India, and the United States.

As the baseline model for each difficulty mindset, we fit a CFA with four scale items loading onto a single latent variable. To test configural invariance, we applied no equality constraints. This allowed us to ensure that the number of factors and loading pattern is the same 
across populations. To test weak invariance, we constrained factor loadings to be equal across groups. To test strong invariance, we constrained both intercepts and factor loadings to be equal across the groups. To test strict invariance, we constrained individual item error variances, factor loadings, and intercepts to be equal across groups.

Imposing constraints on structural models always causes model fit to decrease. We evaluated whether the imposition of equality constraints led to a significant decrement in model fit in more restricted models compared to less restricted models with fewer equality constraints.

A number of fit indices have been proposed, each with advantages and disadvantages. Here, we rely on multiple indices of model fit to determine the type of measurement invariance that was evidenced.

One index we rely on is the Bayesian information criterion (BIC) for determining model fit, as the BIC is a penalized-likelihood criterion, i.e., it penalizes more complex models (have more constraints imposed). Lower BIC values indicate better model fit (Wang et al., 2018). Additionally, we rely on $\triangle \mathrm{CFI}$. A change of no more than .010 in CFI is recommended (Chen, 2007; Cheung \& Rensvold, 2002) to demonstrate invariance. We also report $\chi^{2}$ scores as it reveals whether the decrease in model fit is substantial, however, we do not rely on these scores as $\chi^{2}$ scores are sensitive to sample size (Oishi, 2007).

In the case of difficulty-as-improvement, the strong MI model had the lowest BIC despite the imposition of equality constraints in this model. Based on BIC, the structure, factor loadings, and intercepts of the difficulty-as-improvement measure are similar across the societies in our sample. Based on $\triangle$ CFI however, we can conclude that the structure and factor loadings, but not item intercepts are similar across societies.

In the cases of difficulty-as-importance (Table S8) and difficulty-as-impossibility (Table S9), both BIC and $\triangle \mathrm{CFI}$ indices point to the weak MI model as the model with the best fit. This suggests that the measures' original factor structure works well across the populations and factor loadings are also similar, while item intercepts may not be equal across groups.

We furthermore ran analyses to assess whether we can establish partial invariance, using the methods outlined by Hirschfeld \& von Brachel (2014). We inspected modification indices for individual parameters in the strong-invariance model, specifically, modification indices that pertain to intercepts. There were no modification indices $>10$. To confirm that relaxing constraints would not improve model fit, we fitted four different models, each in which we relaxed the equality constraint for one of the four item intercepts. These models did not show improvement in fit. Hence we did not find evidence for partial invariance for the difficulty mindsets. Complete analyses can be found in the R Markdown file in our OSF folder. 
DIFFICULTY-AS-IMPROVEMENT SUPPLEMENTAL MATERIALS 37

\section{Table S8}

Difficulty-as-Importance Measurement Invariance Models Across Eight Societies

\begin{tabular}{|c|c|c|c|c|c|c|c|}
\hline Model & $\chi^{2}$ & $\Delta \chi^{2}$ & $d f$ & $\Delta d f$ & CFI & $\Delta \mathrm{CFI}$ & BIC \\
\hline Configural & 31.10 & - & 16 & - & .997 & - & 32841 \\
\hline Weak MI & 85.60 & $43.16^{* *}$ & 37 & 21 & .988 & .010 & 32729 \\
\hline Strong MI & 447.61 & $359.20 * * *$ & 58 & 21 & .857 & .130 & 32923 \\
\hline Strict MI & 563.27 & $103.56^{* * *}$ & 65 & 7 & .815 & .043 & 32983 \\
\hline
\end{tabular}


DIFFICULTY-AS-IMPROVEMENT SUPPLEMENTAL MATERIALS 38

\section{Table S9}

Difficulty-as-Impossibility Measurement Invariance Models Across Eight Societies

\begin{tabular}{|c|c|c|c|c|c|c|c|}
\hline Model & $\chi^{2}$ & $\Delta \chi^{2}$ & $d f$ & $\Delta d f$ & CFI & $\Delta \mathrm{CFI}$ & BIC \\
\hline Configural & 59.86 & - & 16 & - & .993 & - & 33529 \\
\hline Weak MI & 91.20 & 27.41 & 37 & 21 & .990 & .003 & 33394 \\
\hline Strong MI & 327.67 & $233.26^{* * *}$ & 58 & 21 & .929 & .061 & 33463 \\
\hline Strict MI & 767.95 & $327.24 * * *$ & 65 & 7 & .810 & .118 & 33847 \\
\hline \multicolumn{8}{|c|}{$\begin{array}{l}\text { Note. } * * * p<.001 . \mathrm{MI}=\text { measurement invariance; Configural }=\text { equal structure, but varying } \\
\text { loadings, intercepts, and residual variances; Weak MI = equal structure and loadings, but varying } \\
\text { intercepts and residual variances; Strong MI = equal structure, loading, and intercepts, but } \\
\text { varying residual variances; Strict MI = equal structure, loading, intercepts, and residual } \\
\text { variances; } d f=\text { degrees of freedom; CFI = comparative fit index; BIC = Bayesian information } \\
\text { criterion. }\end{array}$} \\
\hline
\end{tabular}


DIFFICULTY-AS-IMPROVEMENT SUPPLEMENTAL MATERIALS 39

\section{H5 Supplemental Analyses and Results: The Relationships in H4 are Robust to Controlling for Individual Differences in Intelligence Mindset}

In the motivation literature, growth mindset (the belief that intelligence is malleable) is often measured using statements that are written as fixed mindset items (the belief that intelligence is fixed, Costa \& Faria, 2018). We followed this convention, using statements from Dweck et al. (1995). In Studies 2-9, 11 and 12, we collected measures of growth mindset of intelligence (randomized together with the difficulty mindset items). Growth mindset was measured using four items: You have a certain amount of ability and you can't really do much to change it; Your ability is something about you that you can't change very much; To be honest, you can't really change how able you are; You can learn new things, but you can't really change your basic abilities.

In Study 10, in which we collected data from Chinese participants, the scale was translated into Chinese. However, unlike in English, where the growth mindset items have sometimes used the word "ability" and other times used the word "intelligence" without issue, the same is not true in the Chinese language. In the Chinese language, the words "ability" and "intelligence" are perceived very differently. Multiple native Chinese pilot-testers told us that the direct translation of the four growth mindset items felt highly disfluent and did not make sense. Hence, we used seven items: two in the fixed mindset direction using the term "ability" (these were judged disfluent by our pilot testers), three in the fixed mindset direction using the term "intelligence", and two in the growth mindset direction using the term "ability". Items 1-3 and 67 in the list below have been previously used in Chinese samples (Chongzeng Bi, private communication). The items are listed below (Google translations are shown in parentheses):

1. Fixed 1: 人们可以学习新事物, 但不能真的改变自己的基础智力。(People can learn new things, but cannot really change their underlying intelligence.)

2. Fixed 2: 智力对于个人而言就是不能有很大改变的。 (Intelligence cannot be changed much for an individual.)

3. Fixed 3: 一个人的智力水本是一定的, 难以让它产生多少改变。(A person's intelligence level is certain, and it is difficult to make it change much.)

4. Fixed 4: 你可以学习新事物, 但你的能力是无法改变的。(You can learn new things, but your abilities cannot be changed.)

5. Fixed 5: 你有一定限度的能力, 你无法做什么真的去改变它。(You have a certain limit of ability and there is nothing you can do to really change it.)

6. Growth 1: 不管是谁, 都可以显著改变自己的能力水本。(Anyone can significantly change their level of ability.)

7. Growth 2: 不管一个人的能力水本如何, 总是能够显著改变的。(Regardless of one's ability level, it can always change significantly.)

Exploratory factor analysis revealed a three-factor solution (parallel analysis suggested three eigenvalues $>1$ ). We ran a factor analysis using varimax rotation and minimum residuals 
estimation. Factor loadings can be seen in Table S10. We hence created three scale scores by averaging the items for each factor: fixed-intelligence (items 1-3), fixed-ability (items 3 and 4), growth-ability (items 6 and 7). The two fixed scales were positively (though not redundantly) correlated with each other, $r(117)=.51, p<.001$. Neither fixed-intelligence, $r(118)=-.11, p=$ .21 , nor fixed-ability, $r(117)=-.17, p=.07$, however, were significantly correlated with growthability.

\section{Table S10}

Factor Loadings for Fixed and Growth Mindset Items in Chinese Sample

\begin{tabular}{ccccc}
\hline Item & Fixed-ability & Fixed-intelligence & Growth-ability & Communality (h2) \\
\hline Fixed 3 & .93 & .14 & -.08 & 0.89 \\
Fixed 1 & .78 & .14 & -.04 & 0.64 \\
Fixed 2 & .73 & .29 & -.03 & 0.62 \\
Fixed 5 & .21 & .97 & -.07 & 1.00 \\
Fixed 4 & .43 & .51 & -.15 & 0.46 \\
Growth 1 & -.10 & -.02 & .99 & 1.00 \\
Growth 2 & -.01 & -.08 & .53 & 0.28 \\
\hline
\end{tabular}

The means of the growth mindset scale by society are presented in Table S11. Given that the mean of the fixed-ability items in China looked comparable to the means in the other countries, we used the fixed-ability score in our mixed-effects regression described next.

Table S11 presents the correlations between fixed mindset and the three interpretations of difficulty by society. Correlations reveal that mindset is generally weakly correlated with difficulty-as-importance and difficulty-as-improvement and more strongly correlated with difficulty-as-impossibility. These results converge with Fisher and Oyserman (2017) who report that growth mindset related to difficulty-as-impossibility but orthogonal to difficulty-asimportance. We show that fixed mindset is orthogonal to difficulty-as-improvement. 
DIFFICULTY-AS-IMPROVEMENT SUPPLEMENTAL MATERIALS 41

\section{Table S11}

Correlations of Fixed Mindset with Difficulty Mindset by Society

\begin{tabular}{|c|c|c|c|c|c|}
\hline \multirow[t]{2}{*}{ Country } & \multirow[t]{2}{*}{ Study \# } & \multirow[t]{2}{*}{$M(\mathrm{SD})$} & \multicolumn{3}{|c|}{$\begin{array}{c}\text { Correlation of Fixed Mindset With Inferences About } \\
\text { What Difficulty Implies, Difficulty-as- }\end{array}$} \\
\hline & & & Importance & Impossibility & Improvement \\
\hline Australia & 2 and 6 & $2.91(1.11)$ & $-.23^{* * *}$ & $.63^{* * * *}$ & $-.27^{* * *}$ \\
\hline Canada & 3 and 7 & $2.71(1.18)$ & $-.17^{* *}$ & $.70^{* * *}$ & $-.24^{* * *}$ \\
\hline New Zealand & 4 and 8 & $2.70(1.09)$ & $-.15^{*}$ & $.64^{* * * *}$ & $-.30^{* * *}$ \\
\hline U.S. & 5 and 9 & $2.77(1.15)$ & $-.19^{* * *}$ & $.65^{* * *}$ & $-.25^{* * *}$ \\
\hline $\begin{array}{l}\text { China (fixed } \\
\text { intelligence) }\end{array}$ & 10 & $3.41(1.23)$ & .09 & $.38^{* * *}$ & .11 \\
\hline $\begin{array}{l}\text { China (fixed } \\
\text { ability) }\end{array}$ & 10 & $2.66(1.07)$ & .01 & $.62^{* * * *}$ & $-.20^{*}$ \\
\hline China (growth) & 10 & $4.24(1.03)$ & .17 & -.08 & $.42^{* * *}$ \\
\hline Iran & 11 & $2.46(0.97)$ & -.05 & $.58^{* * * *}$ & -.06 \\
\hline Turkey & 12 & $2.46(1.19)$ & $.15^{*}$ & $.55^{* * *}$ & -.01 \\
\hline
\end{tabular}


Next, we examined whether the mindsets predicted our identity construction outcomes measures, after controlling for each other and for growth mindset (for this analysis, we used only the fixed-ability mindset items for study 10). In other words, we conducted four mixed-effects regressions, with all four mindsets (difficulty-as-improvement, difficulty-as-importance, difficulty-asimpossibility, and growth mindset) entered as the predictors and with society as a random effect. Figure S1 shows the standardized $\beta$ coefficients for each model.

\section{Figure S1}

Each Interpretation of Difficulty is Uniquely Associated with Identities of Resilience, Even When Controlling for Fixed Mindset

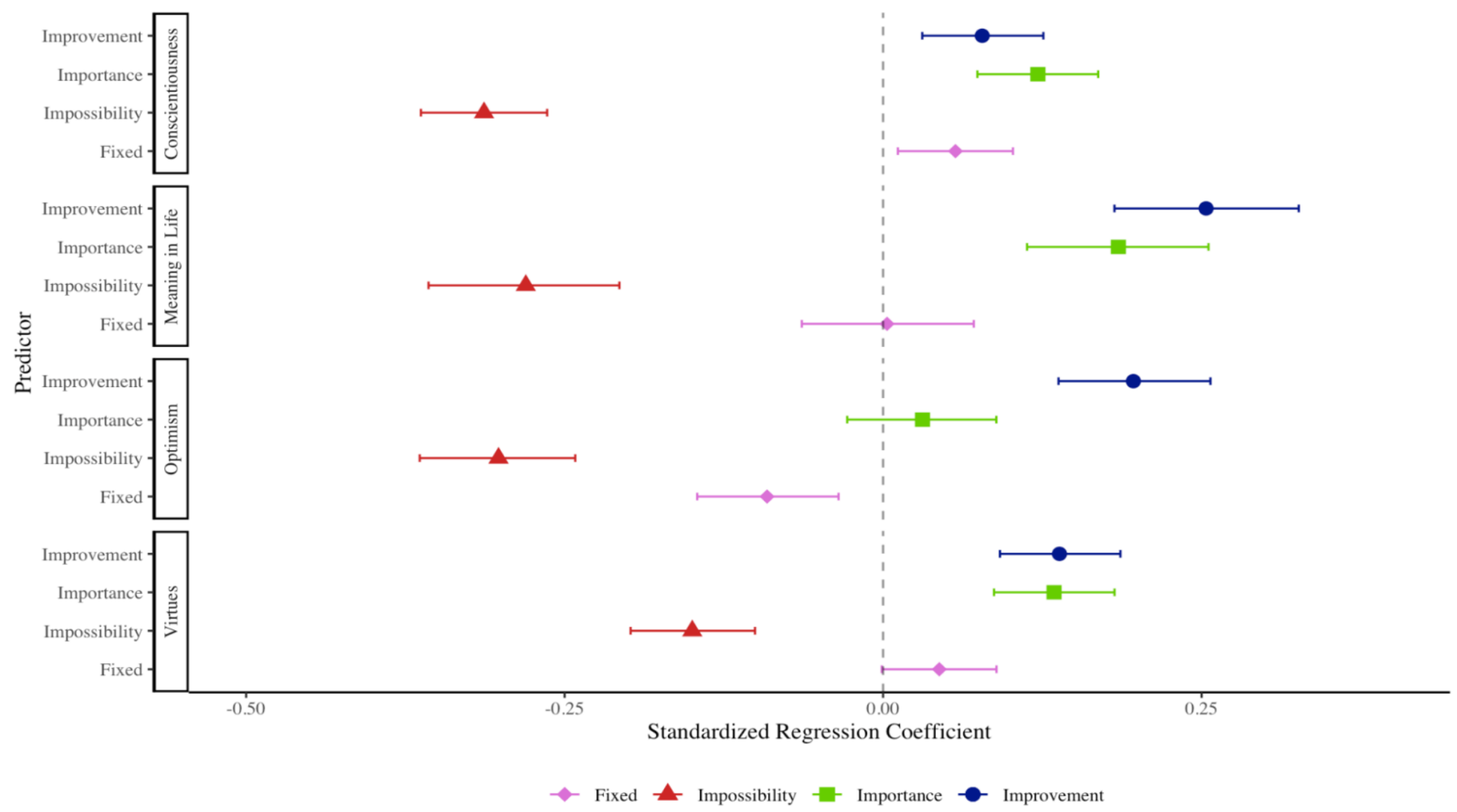


H6 Supplemental Analyses and Results: People who Believe in Karma and a Just World, are Religious, Spiritual, and Conservative Endorse Difficulty-as-Improvement More

\section{Table S12}

Correlation Matrix of Cultural Frames

\begin{tabular}{|c|c|c|c|c|c|c|}
\hline Scale & $\begin{array}{c}M \\
(\mathrm{SD})\end{array}$ & Karma & $\begin{array}{l}\text { Just } \\
\text { World } \\
\text { Beliefs }\end{array}$ & Religiosity & Spirituality & Conservatism \\
\hline Karma & $\begin{array}{c}3.90 \\
(1.08)\end{array}$ & & $.67^{* * *}$ & $.61^{* * *}$ & $.56^{* * *}$ & $.39^{* * *}$ \\
\hline $\begin{array}{l}\text { Just World } \\
\text { Beliefs }\end{array}$ & $\begin{array}{c}4.08 \\
(0.83)\end{array}$ & & & $.49^{* * *}$ & $.45^{* * *}$ & $.31^{* * *}$ \\
\hline Religiosity & $\begin{array}{c}3.62 \\
(1.62)\end{array}$ & & & & $.90^{* * *}$ & $.45^{* * * *}$ \\
\hline Spirituality & $\begin{array}{c}3.93 \\
(1.46)\end{array}$ & & & & & $.38^{* * *}$ \\
\hline Conservatism & $\begin{array}{c}3.07 \\
(1.39)\end{array}$ & & & & & \\
\hline
\end{tabular}

Note. Results pool data from Studies 13 and 14. *** $p<.001$. 
Table S13 shows the multivariate regression equations with five cultural antecedent measures and society (the U.S. vs. India) simultaneously considered as predictors, and difficultyas-improvement as the outcome. Figure S2 shows a forest plot for standardized beta coefficients.

Table S13

Cultural Antecedents are Associated with Difficulty-as-Improvement: Linear Regression Results

\begin{tabular}{ccccc}
\hline Predictor & $\beta$ & $\beta 95 \%$ CI & $t$ statistic & $p$ \\
\hline Karma & .25 & {$[.17, .34]$} & 6.06 & $<.001$ \\
Just World & .25 & {$[.17, .32]$} & 6.62 & $<.001$ \\
Spirituality & .13 & {$[.01, .26]$} & 2.13 & .033 \\
Religiosity & .05 & {$[-.08, .18]$} & 0.76 & .446 \\
Conservatism & -.05 & {$[-.10,-.01]$} & -2.40 & .017 \\
Society (U.S.) & -.14 & {$[-.27,-.01]$} & -2.06 & .040 \\
\hline Adjusted $R^{2}$ & & .43 & \\
\hline$F$-statistic & \multicolumn{5}{c}{$81.18 * * *(6,646)$} \\
\hline
\end{tabular}

Note. $* * * p<.001$. 


\section{Figure S2}

Unique Associations between Difficulty-as-Improvement and Cultural Antecedents (Conservatism, Religiosity, Spirituality, Just World Beliefs, and Karma) Controlling for Society, and Each of the Other Antecedents

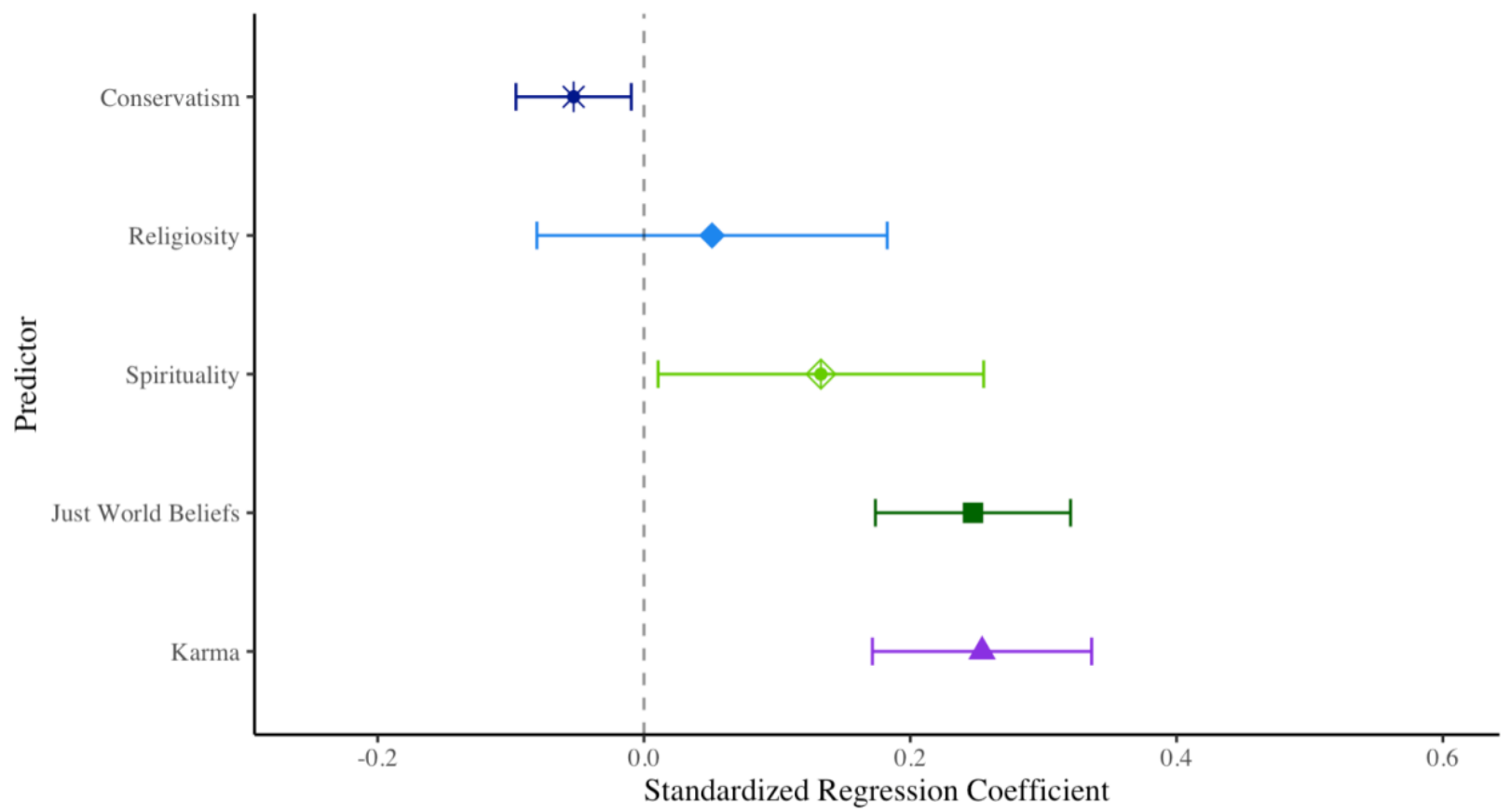

Note. Points represent standardized beta coefficients; whiskers represent $95 \%$ confidence intervals. Results reflect coefficients from a multivariate regression with all of the cultural antecedent constructs entered simultaneously, as well as society (U.S., India; for simplicity's sake, is not shown in figure). 
DIFFICULTY-AS-IMPROVEMENT SUPPLEMENTAL MATERIALS 46

\section{References}

Chen, F. F. (2007). Sensitivity of goodness of fit indexes to lack of measurement invariance. Structural Equation Modeling: A Multidisciplinary Journal, 14(3), 464-504. https://doi.org/10.1080/10705510701301834

Chen, F. F. (2008). What happens if we compare chopsticks with forks? The impact of making inappropriate comparisons in cross-cultural research. Journal of Personality and Social Psychology, 95(5), 1005. https://doi.org/10.1037/a0013193

Cheung, G., \& Rensvold, R. (2002). Evaluating goodness-of-fit indexes for testing measurement invariance. Structural Equation Modeling, 9(2), 233-255. https://doi.org/10.1207/s15328007sem0902_5

Costa, A., \& Faria, L. (2018). Implicit theories of intelligence and academic achievement: A meta-analytic review. Frontiers in Psychology, 9, Article 829. https://doi.org/10.3389/fpsyg.2018.00829

Dweck, C., Chiu, C. Y., \& Hong, Y. Y. (1995). Implicit theories and their role in judgments and reactions: A word from two perspectives. Psychological Inquiry, 6(4), 267-285. https://doi.org/10.1207/s15327965pli0604_1

Fischer, R., \& Karl, J.A. (2019). A Primer to (Cross-Cultural) Multi-Group Invariance Testing Possibilities in R. Frontiers in Psychology, 10, Article 1507. https://doi.org/10.3389/fpsyg.2019.01507

Fisher, O., \& Oyserman, D. (2017). Assessing Interpretations of Experienced Ease and Difficulty as Motivational Constructs. Motivation Science, 3(2), 133-163. https://doi.org/10.1037/mot0000055

Hirschfeld, G., \& Von Brachel, R. (2014). Improving Multiple-Group confirmatory factor analysis in $\mathrm{R}-\mathrm{A}$ tutorial in measurement invariance with continuous and ordinal 
DIFFICULTY-AS-IMPROVEMENT SUPPLEMENTAL MATERIALS 47

indicators. Practical Assessment, Research, and Evaluation, 19(1), Article 7.

\section{https://doi.org/10.7275/qazy-2946}

John, O. \& Srivastava, S. (1999). The Big Five trait taxonomy: History, measurement, and theoretical perspectives. In L. Pervin \& O. John (Eds.), Handbook of Personality: Theory and Research, $2^{\text {nd }}$ ed., pp. 102-138. Guilford.

Jorgensen, T. D., Pornprasertmanit, S., Schoemann, A. M., \& Rosseel, Y. (2021). semTools: Useful tools for structural equation modeling. R package version 0.5-5. Retrieved from https://CRAN.R-project.org/package=semTools

Koenig, H., \& Büssing, A. (2010). The Duke University Religion Index (DUREL): A five-item measure for use in epidemiological studies. Religions, 1(1), 78-85.

https://doi.org/10.3390/rel1010078

Lipkus, I., Dalbert, C., \& Siegler, I. (1996). The importance of distinguishing the belief in a just world for self versus for others: Implications for psychological well-being. Personality and Social Psychology Bulletin, 22(7), 666-677. https://doi.org/10.1177/0146167296227002

McGrath, R. (2015). Integrating psychological and cultural perspectives on virtue: The hierarchical structure of character strengths. The Journal of Positive Psychology, 10(5), 407-424. http://dx.doi.org/10.1080/17439760.2014.994222

McGrath, R. E. (2017). Technical report: The VIA Assessment Suite for Adults: Development and initial evaluation. Cincinnati, $\mathrm{OH}$ : VIA Institute on Character.

McGrath, R. E., Greenberg, M. J., \& Hall-Simmonds, A. (2018). Scarecrow, Tin Woodsman, and Cowardly Lion: The three-factor model of virtue. The Journal of Positive Psychology, 13(4), 373-392. https://doi.org/10.1080/17439760.2017.1326518

Newman, D., Schwarz, N., Graham, J., \& Stone, A. (2018). Conservatives report greater 
DIFFICULTY-AS-IMPROVEMENT SUPPLEMENTAL MATERIALS 48

meaning in life than liberals. Social Psychological and Personality Science, 10(4), 494503. https://doi.org/10.1177/1948550618768241

Oishi, S. (2007). The application of structural equation modeling and item response theory to cross-cultural positive psychology research. In A. D. Ong \& M. H. M. van Dulmen (Eds.), Oxford Handbook of Methods in Positive Psychology (pp. 126-138). New York, NY: Oxford University Press.

Rosseel, Y. (2012). Lavaan: An R package for structural equation modeling and more. Version 0.5-12 (BETA). Journal of Statistical Software, 48(2), 1-36.

Scheier, M., Carver, C., \& Bridges, M. (1994). Distinguishing optimism from neuroticism (and trait anxiety, self-mastery, and self-esteem): a reevaluation of the Life Orientation Test. Journal of Personality and Social Psychology, 67(6), 1063-1078.

Steger, M., Frazier, P., Oishi, S., \& Kaler, M. (2006). The meaning in life questionnaire: Assessing the presence of and search for meaning in life. Journal of Counseling Psychology, 53(1), 80-93. https://doi.org/10.1037/0022-0167.53.1.80

Wang, S., Chen, C. C., Dai, C. L., \& Richardson, G. B. (2018). A call for, and beginner's guide to, measurement invariance testing in evolutionary psychology. Evolutionary Psychological Science, 4(2), 166-178. https://doi.org/10.1007/s40806-017-0125-5

White, C., Norenzayan, A., \& Schaller, M. (2019). The content and correlates of belief in Karma across cultures. Personality and Social Psychology Bulletin, 45(8), 1184-1201. https://doi.org/10.1177/0146167218808502 